\title{
LAS SENTENCIAS PILOTO COMO EJEMPLO PARADIGMÁTICO DE LA TRANSFORMACIÓN DEL TRIBUNAL DE EUROPEO DE DERECHOS HUMANOS
}

\author{
ARGELIA QUERALT JIMÉNEZ \\ Profesora Agregada de Derecho Constitucional \\ Universidad de Barcelona
}

\begin{abstract}
SUMARIO
I. Introducción. II. El atasco de casos ante el Tribunal Europeo. III. La transición de lo internacional a lo constitucional. IV. La aparición de las sentencias piloto. V. Práctica y alcance de las sentencias piloto. VI. La tendencia constitucionalizadora del procedimiento piloto. VII. Un claro desafío a la función de tutela individual. VIII. Valoraciones finales.
\end{abstract}

\section{INTRODUCCIÓN ${ }^{1}$}

Después de 60 años de funcionamiento del sistema europeo de garantía de los derechos fundamentales y de más de 50 años desde que el Tribunal Europeo de Derechos Humanos (TEDH) dictara su primera sentencia, ha llegado el momento de replantearse la función definitoria de esta jurisdicción, como viene haciendo parte de la doctrina europea en los últimos

1 Las páginas que siguen pertenecen a un estudio más amplio sobre «La transformación de la función del TEDH en el espacio judicial europeo de los derechos humanos» que presenté como ejercicio de investigación en el concurso para acceder a un contrato de profesora de Agregada Serra Hunter, convocatoria 2016, celebrado el mes de mayo de 2018. Algunas de las conclusiones alcanzadas hasta ahora son fruto de una estancia de tres meses en el Max Planck Institut für ausländisches öffentliches Recht und Völkerrecht en Heidelberg, Alemania, donde fui recibida por el prof. A. Von Bogdandy. Durante esta estancia tuve la oportunidad de discutir mi trabajo con diferentes investigadores europeos y latinoamericanos, algunos de ellos pertenecientes a la Red ICCAL (Ius Constitutionale Commune en América Latina), impulsada por la Prof. Mariela Morales ANTONIAZZI a quien agradezco enormemente que me haya incorporado en esta red magnífica. Asimismo, quiero agradecer al Prof. Luis LóPEz GuERra a quien entrevisté en Estrasburgo en su calidad del magistrado el TEDH y a Guillem CANO-PALOMAREs, Letrado del Tribunal, a quien asalto constantemente con mis dudas. El estudio sobre completo del nuevo papel del TEDH en Europa verá la luz en forma de monografía en los próximos meses. Y como siempre, al grupo de investigación dirigido por el prof. J. García Roca y, tras el fallecimiento del profesor y amigo P. Santolaya, y la profa. E. Carmona Cuenca con quienes debatir siempre supone aprender. 
tiempos ${ }^{2}$. En esta línea, merece la pena reconocer y analizar con detalle la tensión existente entre su función de tutela individual, que ha sido siempre identificada como el objetivo central del sistema europeo, y su función como fijadora de estándares en materia de derechos y libertades. A esta tensión ya se han referido diferentes autores, por todos, L. Wildhaber quien la identificaba como la «fundamental dichotomy» del sistema ${ }^{3}$. Se trata, utilizando un lenguaje más proprio del derecho constitucional, de profundizar en la tensión existente entre la tutela subjetiva de los derechos y una tutela de tipo objetivo y, en cierto sentido, la posibilidad de identificar al TEDH como el tribunal constitucional europeo ${ }^{4}$.

Es evidente que, durante más de 5 décadas de funcionamiento del sistema europeo, el TEDH se ha reivindicado muy especialmente como una jurisdicción internacional a través de la que los particulares podían ver tutelados sus derechos; ahora bien, esta protección quizá no necesariamente deba hacerse a través de las demandas individuales 5 . Se trata pues, de nuevo en palabras del ex-Presidente L. Wildhaber, de entender la demanda individual como un medio, y como un fin en si mismo. Además, los cambios en la configuración del Tribunal, su propia práctica y lógica de funcionamiento, y su jurisprudencia hacen pensar que esta jurisdicción es consciente de que su función en el escenario europeo está cambiando. Cabe identificar una tendencia creciente en el propio TEDH, no siempre explícita, hacia la priorización de la función armonizadora, establecedora de estándares comunes, en detrimento de su función eminentemente tuitiva, basada en un análisis caso a caso. Muestra de ello son, por ejemplo, el reconocimiento, todavía implícito, de los efectos vinculantes y erga omnes de la cosa interpretada; el desarrollo de instrumentos internos en el TEDH para dotar de mayor coherencia a las decisiones de las diferentes Salas y evitar contradicciones ${ }^{6}$; el fomento del estudio y aproximación comparados a los conflictos para dotar de base a los consensos de los que el TEDH suele hacer uso en sus decisiones; la insistencia en la subsidiariedad del sistema; los esfuerzos de la Gran Sala por establecer criterios generales en sus sentencias; la tendencia del sistema hacia la estandarización y concentración en problemas estructurales. Entre estas novedades, destaca la que es el objeto de estas páginas: el desarrollo y perfeccionamiento del procedimiento de las sentencias piloto.

Esta tendencia armonizadora, viene seguramente obligada por un elemento bastante prosaico: el TEDH necesita de una nueva estrategia para afrontar su, de nuevo, creciente atasco de demandas (lo que en la jerga de Estrasburgo se categoriza como medidas para garantizar la efectividad a largo plazo del sistema).

Está claro, en todo caso, que el Tribunal está en una nueva etapa de redefinición que, como señala la doctrina, implica una transformación de su posición en el espacio judicial europeo. Veremos cómo contribuyen a ello las sentencias piloto.

2 GLAs, L. R. «Changes in the Procedural Practice of the European Court of Human Rights: Consequences for the Convention System and Lessons to Be Drawn,» Human Rights Law Review 14, no. 4, pp. 671-690.

3 Wildhaber, L. «A Constitutional Future for the European Court of Human Rights?,» Human Rights Law Journal, no. 23 (2002), p. 162.

4 En esta línea también se manifiesta De Londras, F. «Dual Functionality and the Persistent Frailty of the European Court of Human Rights,» European Human Rights Law Review, 2013(1), pp.38-46.

5 En esta línea, Gerards J. H. y Glas, L. R. «Access to Justice in the European Convention on Human Rights System,» Netherlands Quarterly of Human Rights 35, no. 1, pp. 11-30.

6 Muy relevante es la figura del Jurisconsulto ahora prevista en el art. 18 RTEDH. 


\section{EL ATASCO DE CASOS ANTE EL TRIBUNAL EUROPEO}

Las cifras del TEDH son siempre un instrumento recurrente para mostrar cual es la situación real del sistema europeo ${ }^{7}$ :

a) a finales de 2017 había aproximadamente 56250 demandas pendientes ante alguna de las formaciones judiciales del TEDH

b) durante 2017 unas 63400 demandas fueron asignadas a alguna de las formaciones del Tribunal';

c) el TEDH dictó 1068 sentencias que resolvían 15595 demandas.

d) 70356 asuntos fueron declarados inadmisibles o fueron $\operatorname{archivados}^{10}$ (66156 por un juez único).

e) en cambio, tan sólo fueron admitidos 531 asunto, un 0,9\% del total de demandas interpuestas.

Con estas cifras cabe hacerse una primera idea de a qué tipo de demandas hace frente al TEDH diariamente, en otros términos, a qué tipo de asuntos está dedicando tiempo y recursos.

El continuado aumento de demandas se debe a la entrada de nuevos Estados y al mayor conocimiento que se tiene hoy del sistema europeo, pero, también, como señala Helfer $^{11}$ a la buena reputación con la que cuenta el TEDH entre la opinión pública, su interpretación extensiva del $\mathrm{CEDH}$, la desconfianza respecto de los jueces internos en algunos Estados, o a problemas arraigados en los sistemas de derechos fundamentales en el ámbito doméstico.

La supervivencia del sistema viene siendo objeto de preocupación desde hace muchos años en el seno del Consejo de Europa; de hecho, tras la entrada en vigor del Protocolo núm. 11 al CEDH en 1998, se produjo la primera toma de consciencia de que aquella reforma que había convertido al sistema europeo en único en su especie debería pronto ser seguida de nuevas modificaciones que ayudaran a aligerar la carga del trabajo del $\mathrm{TEDH}^{12}$. Sin embargo, como señalan Greer y Wildhaber ${ }^{13}$, el debate oficialista que

7 Las cifras utilizadas han sido extraídas de las publicación del TEDH «Analysis of statistics 2017», publicado en enero de 2018, y que puede encontrarse en https://www.echr.coe.int/Documents/Stats_analysis_2017_ ENG.pdf.

8 A 31 de diciembre de 2017 había una bolsa de 12,600 demandas en una fase-prejudicial.

De hecho, en 2017 hubo una gran fluctuación en el número de demandas: en enero había 79750 demandas pendientes, 93200 en junio, y 5625 en diciembre. La diferencia entre la cifra de enero y la de finales de año es esencialmente el efecto de que los casos sean repatriados al sistema nacional de una forma u otra, especialmente tras una sentencia piloto.

9 Si bien fui capaz de encontrar la cifra de demandas repetitivas a 31 de diciembre de 2016 ante el TEDH, 35000 demandas, no lo he podido hacer con las cifras publicadas en la web respecto de 2017.

10 Cabe adelantar ahora que 12148 demandas fueron archivadas en una sentencia de la Gran Sala (Burmych y otros contra Ucrania, el 12 de octubre de 2017), de seguimiento de una sentencia piloto previa.

11 Helfer, L. R. «Redesigning the European Court of Human Rights: Embeddedness as a Deep Structural Principle of the European Human Rights Regime,» The European Journal of International Law EJIL 19, no. 1 , p. 133.

12 Cfr. Queralt Jiménez, A. El Tribunal de Estrasburgo: Una jurisdicción internacional para la protección de los derechos fundamentales, Tirant lo Blanch, Valencia, 2003, capítulo 2.

13 Greer, S. y Wildhaber, L. «Revisiting the Debate about 'constitutionalising' the European Court of Human Rights,» Human Rights Law Review 12, no. 4, pp. 5 y ss. 
defienden la mayoría de los implicados en el Consejo de Europa impide entrar a discutir sobre las bases mismas del sistema europeo de garantía, quedándose, por el contrario, en la propuesta de reformas superficiales, en "parches», que no permiten una mejora sustancial del sistema (estos autores hablan literalmente de «procrastination and tinkering» ${ }^{14}$ ). Por contra, el debate mantenido por jueces y en la academia resulta bastante más profundo y plantea seriamente repensar la función del TEDH. En esta línea es oportuno adentrarse en el estudio de cómo priorizar una función sobre otra de forma que se permita al TEDH velar más adecuadamente por los derechos y libertades del CEDH en Europa, respetando la subsidiariedad del sistema. El objetivo, es, por tanto, aportar un nuevo enfoque (Helfer apuesta por un «rediseño» ${ }^{15}$ ) sobre cómo debe abordar el Tribunal de Estrasburgo su función de garante.

\section{LA TRANSICIÓN DE LO INTERNACIONAL A LO CONSTITUCIONAL}

\section{El proceso de armonización}

En la línea apuntada, es necesario abordar la naturaleza del Tribunal de Estrasburgo, desde una perspectiva más abierta y material. Parece claro que el TEDH desarrolla una función que supera, con creces, la primigenia finalidad de los tribunales internacionales de resolver conflictos internacionales e, incluso, los planteamientos de los Estados fundadores del Consejo de Europa y primeros firmantes del Convenio Europeo $^{16}$. Por este motivo, muchos autores tratan de categorizar al TEDH más allá de su naturaleza formalmente internacional. Así, S. Besson ${ }^{17}$ afirma que hoy cabe defender que el control judicial que lleva a cabo el Tribunal Europeo se acerca más al de una jurisdicción supranacional o constitucional, que a un tribunal internacional clásico. Otras autoras, como muestra de la nueva función material del TEDH, se centran en su impacto, como J. Gerards quien que se refiere al poder transformador (transformative power) del Tribunal ${ }^{18}$. Algunos autores no dudan en atribuirle una función constitucional debido precisamente al tipo de control que realiza y los efectos de sus sentencias en los ordenamientos internos ${ }^{19}$.

En este contexto debe explicarse cual es la naturaleza actual del TEDH, a partir de su función en el escenario europeo, para poder entender cual es su relación con el resto

14 Greer, S. y Wildhaber, L., «Revisiting the Debate...», op. cit. p. 7.

15 Helfer, L. R. «Redesigning the European Court of Human Rights»..., op.cit., 128.

16 Recuérdese que el CEDH contendía un mecanismo de protección muy diferente al actual en su estructura y naturaleza; cfr. Queralt JimÉNEZ, A. El Tribunal de Estrasburgo, op. cit.

17 Besson, S. «European Human Rights, supranational judicial review and democracy», en Popelier, P., HeYning, C., Nuffel, P. V. Human rights protection in the European legal order: the interaction between the European and the national courts, Intersetia, Bélgica, 2011, pp. 112 en especial.

18 Gerards, J. H. «The Paradox of the European Convention on Human Rights and the European Court of Human Rights' Transformative Power,» Kutafin University Law Review 4, no. 2, pp. 319 y ss.

19 Entre otros, SADURSKI, W. «Partnering with Strasbourg: Constitutionalisation of the European Court of Human Rights, the Accession of Central and East European States to the Council of Europe, and the Idea of Pilot Judgments», en Human Rights Law Review, vol. 93, 2009, pp. 397-453; o los ya citados Greer, S., y WiLDHABER, L. o DE LONDRAS, F. 
órganos de tutela de los derechos fundamentales (en sentido amplio), sobre todo, en el ámbito doméstico. De acuerdo con mis últimas investigaciones, el papel del TEDH en Europa cabe ser explicado a través de su función armonizadora. Para ello debe ponerse en valor la gran aportación del Tribunal de Estrasburgo a la protección de los derechos y libertades en Europa, enfatizando su contribución en la creación de un ius commune europeo de los derechos humanos («comunidad de derecho» según $\mathrm{Helfer}^{20}$ ), que se genera a través de función de standard setting y que impacta en los sistemas domésticos europeos, provocando cambios en ellos.

La armonización es un proceso basado en el efecto de cosa interpretada de las sentencias del TEDH en el que llevo trabajando desde hace años ${ }^{21}$. El Tribunal Europeo parece haber reconocido, no siempre de forma clara, la cosa interpretada como uno de los efectos inherentes a sus sentencias, pero no ha dado el paso de defender su carácter vinculante, no al menos de forma expresa ${ }^{22}$. Esto no le ha impedido, sin embargo, utilizar su propia jurisprudencia para determinar cuál es el estándar respecto de cada uno de los derechos y libertades convencionales y establecerlo como el canon de convencionalidad que debe ser respetado por las autoridades internas de cualquiera de los Estados parte, y no sólo el implicado en un determinado caso. Y ello porque el efecto de cosa interpretada es erga omnes.

La razón que me lleva a defender el carácter vinculante del efecto de cosa interpretada está en que la vinculatoriedad interpretativa de las sentencias del TEDH es elemento indispensable para la supervivencia del propio sistema y elemento indisociable a unos sistemas que se erigen en «desarrolladores» de estándares en materia de derechos humanos en sus respectivos territorios. Esta es, también, la posición que cada vez más agentes implicados en funcionamiento de la garantía europea que el seguimiento del canon europeo, formado por el catálogo convencional y el desarrollo hecho por el Tribunal, es un instrumento indispensable para garantizar la subsistencia del sistema.

Las bases de esta construcción teórica son, en síntesis, las siguientes: los Estados cuando se obligan a respetar los compromisos jurídicos que se derivan del CEDH saben que lo hacen también a la jurisprudencia del TEDH, asumen el compromiso jurídico respecto del acquis convenctionnel europeo. Negar la obligatoriedad de la cosa interpretada de las sentencias definitivas del Tribunal sería tanto como negar la evolución del propio $\mathrm{CEDH}$ y su efectividad actual. Ahora bien, la obligatoriedad que genera la cosa interpretada, que deriva del art. $1 \mathrm{CEDH}$, es de resultado y supone un deber de compatibilidad de los ordenamientos internos con el citado acquis conventionnel. Si un juez interno se

20 Cfr. Helfer, L. R., «Redesigning the European Court of Human Rights», op.cit., p. 134.

21 Especialmente, Queralt Jiménez, A. «Los usos del canon europeo en la jurisprudencia del Tribunal Constitucional: una muestra del proceso de armonización europea en materia de derechos fundamentales», en Teoría y Realidad Constitucional, núm. 20, 2007, pp. 230-275.

22 Es esta una clara diferencia respecto del sistema interamericano de derechos humanos donde la Corte expresamente reconoce los efectos vinculantes y erga omnes de sus sentencias a través del control de convencionalidad. Puede encontrarse un estudio comparado entre el control de convencionalidad americano y la cosa interpretada europea en Ferrer-Macgregor, E., y Queralt Jimenez, A. «El control de convencionalidad americano y el efecto de cosa interpretada europeo ¿dos caras de una misma moneda?», en ¿Hacia la globalización de los derechos? El impacto de las sentencias del Tribunal Europeo y la Corte Interamericana, García Roca, J, y Carmona Cuenca, E., (eds)., Ed. Aranzadi, Cizur Menor, 2017. 
aparta de los estándares fijados por el TEDH podrá provocar una nueva sentencia estimatoria de esta jurisdicción o, quizá, provocar una revisión de su jurisprudencia, pero, en cualquier caso, el Tribunal Europeo será el que decida en última instancia cual es la interpretación compatible con el CEDH en cada momento.

Así, una vez que el Estado ha ratificado válidamente el CEDH aquel quedará obligado por el acquis conventionnel europeo, compuesto por las obligaciones del Convenio y, indisociablemente, por el desarrollo jurisprudencial efectuado por el Tribunal de Estrasburgo. Observar la jurisprudencia del TEDH y compatibilizar los estándares internos con el estándar europeo implica cumplir con la obligación del art. 1 CEDH. En definitiva, es el propio sistema de garantía el que genera un principio general de compatibilidad con el estándar europeo definido, desarrollado, completado en cada momento por la interpretación que el TEDH ofrece en sus sentencias.

Pues bien, en el que podemos denominar el espacio judicial europeo de los derechos y libertades «cohabitan», utilizando el término de C. PIZZOLO ${ }^{23}$, Tribunales ordinarios de distinto tipo y rango, los Tribunales constitucionales y/o supremos de cada Estado con el Tribunal de Justicia de la Unión Europea y el Tribunal Europeo de Derechos Humanos. La base normativa de las relaciones transnacionales y su práctica efectiva son diversas, produciéndose así diálogos, en un sentido amplio, de distinta índole ${ }^{24}$. En esta cohabitación dialógica el instrumento privilegiado de relación entre los tribunales internos (sean del tipo que sean) y el Tribunal Europeo de Derechos Humanos es el efecto de cosa interpretada. La res interpretata es el vehículo de diálogo con el que cuenta el TEDH en esta comunidad de intérpretes ${ }^{25}$ en la que se desarrolla hoy, como se acaba de mencionar, la tutela de los derechos fundamentales. La principal relación entre TEDH y los Tribunales internos, incluidos los Tribunales Constitucionales, en materia de derechos fundamentales se produce a través de los efectos interpretativos de la jurisprudencia del Tribunal de Estrasburgo. Estos efectos interpretativos permiten a todos los poderes públicos, también los judiciales, conocer cual es el estándar europeo en cada momento y adaptar su actividad a dicho estándar. Por este motivo defiendo que el efecto de cosa interpretada de las sentencias europeas permite afirmar que el Tribunal de Estrasburgo es el responsable de un proceso de armonización de estándares de derechos y libertades en el espacio judicial europeo.

El proceso de armonización en materia de derechos y libertades, que no de uniformización, viene exigido por el entendimiento conjunto de la existencia de un estándar mínimo europeo (art. $53 \mathrm{CEDH}$ ) y la asunción del pluralismo sobre el que se asienta el sistema. En este sistema, además, la compatibilidad como principio de no contradicción de las medidas estatales con el estándar mínimo generado por el CEDH y la jurisprudencia del TEDH, y no la identidad o la conformidad, hace efectivo el principio de subsidiariedad del sistema europeo, porque permite a los Estados parte elegir los medios para cumplir efectivamente con las obligaciones derivadas de la ratificación del CEDH, sin

23 Pizzolo, C., Comunidad de intérpretes finales : relación entre Tribunales Supranacionales, Constitucionales y Supremos: el diálogo judicial, Astrea, Buenos Aires, 2017.

24 Entre nosotros, son especialmente relevantes los trabajos de Torres PÉrez, A., Conflict of Rights in the European Union: A Theory of Supranational Adjudication, Oxford University Press, Oxford, 2009, y Bustos GISPERT, R. «XV proposiciones generales para una teoría de los diálogos judiciales», en Revista Española de Derecho Constitucional, núm. 95, 2012, pp. 13-63.

25 De nuevo, acuñado por Pizzolo, C., Comunidad de Intérpretes Finales, op.cit. 
que esto suponga menoscabar la efectividad del sistema ya que el TEDH tendrá la última palabra sobre la potencial contradicción entre las medidas adoptadas por las autoridades nacionales y el estándar europeo.

En definitiva, el proceso de armonización viene implicando a los tribunales ordinarios internos y, particularmente, a los tribunales constitucionales a través de la recepción en sus decisiones del estándar fijado en Estrasburgo, que se convierte en el parámetro de control de la convencionalidad de la actividad de los poderes públicos domésticos. Si no se supera este control, los Estados deben modificar sus cánones internos y reorientarlos hacia el estándar europeo existente.

\section{2. ¿Un tribunal constitucional europeo?}

Algunos autores describen hace tiempo al TEDH como una suerte de tribunal constitucional europeo y ello, no tanto por su composición o naturaleza, sino más bien por la función que desarrolla. Así, si consideramos que es constitucional aquel tribunal que es capaz de anular disposiciones generales, normas jurídicas internas cuando son declaradas como contrarias a un parámetro superior, ¿cabe afirmar que el Tribunal de Estrasburgo es un Tribunal Constitucional? La respuesta será negativa si tomamos la definición anterior en su sentido estricto. Sin embargo, si permitimos cierta flexibilidad interpretativa, cabría afirmar que el TEDH es tendencialmente una jurisdicción constitucional para Europa, el tribunal constitucional del espacio judicial europeo de los derechos humanos. El CEDH no es obviamente una constitución en el sentido clásico del término, aunque el propio Tribunal lo calificase como «a constitutional instrument of european public order (ordre public)» en su STEDH Loizidou contra Turquía, 23 de marzo de 1995. En todo caso, el CEDH se ha convertido en el catálogo de derechos y libertades de referencia en la actividad de las instituciones de 47 Estados y de la Unión Europea. Por su parte, las sentencias del TEDH son obligatorias, aunque no ejecutivas y, por tanto, no implican per ser la anulación de una disposición general interna (sea ley, sea reglamento, sea de la clase que sea). En el ámbito de las medidas individuales, muchos Estados han incorporado en sus ordenamientos una vía para permitir la revisión judicial de sentencias firmes tras una condena del Tribunal Europeo ${ }^{26}$. Además, hay muchísimas evidencias de que los Estados parte modifican, acomodan, sus ordenamientos jurídicos internos, prácticas administrativas e interpretaciones judiciales a los estándares del Tribunal de Estrasburgo y lo hacen independientemente de si fueron o no el Estado declarado responsable de una violación del Convenio. En todo caso, las decisiones del Tribunal no siempre generan la inmediata anulación de una norma interna, como sería exigible de un Tribunal Constitucional «clásico», pero suponen, en muchos casos, el inicio de un camino para su futura (más o menos próxima) modificación ${ }^{27}$.

26 En cumplimiento de la Recommendation No. R (2000) 2 of the Committee of Ministers to member states on the re-examination or reopening of certain cases at domestic level following judgements of the European Court of Human Rights, adoptada el 19 de enero de 2000, muchos Estados han incorporado este instrumento de ejecución de sentencias en sus ordenamientos; recientemente, España.

27 Una muestra de los cambios domésticos provocados por las sentencias del TEDH puede encontrarse en el documento «Thematic presentation of major reforms since Interlaken 2010» (Committe of Ministers' Annual Report 2016, https://rm.coe.int/16807082d4) 
Sadurski, a través de un acercamiento pragmático ${ }^{28}$, afirma que es obvio que no cabe hablar de Constitución cuando nos referimos al CEDH ni de Tribunal Constitucional para definir el TEDH. Sin embargo, considera que si se permite un acercamiento por grados o intensidades (un planteamiento flexible como el que se defiende aquí), entonces sí puede aceptarse que el Tribunal Europeo es en cierto grado constitucional. En su caso, la cuestión de si estamos ante una jurisdicción constitucional tiene que ver con las concretas funciones que lleva a cabo el TEDH y que, como defiende este autor, se han ido constitucionalizando, esto es, se percibe una clara tendencia constitucionalizadora de su actividad. Esta tendencia se ha visto reafirmada por la entrada de los países del este y centro de Europa en el Consejo de Europa. Para Sadurski las deficiencias en los sistemas de tutela de los derechos fundamentales de las nuevas democracias orientales y centro europeas provocaron una clarísima transformación del TEDH hacia su constitucionalización. Y ello porque la entrada de estos Estados en el sistema provocó que el Tribunal de Estrasburgo se viera obligado a pasar de ser una jurisdicción, en el término utilizado por de Sadurski, de «fine-tuned control» a una jurisdicción que debía entrar a valorar la propia viabilidad de sistemas normativos y políticas públicas respecto del estándar común europeo ${ }^{29}$. Ya no se trataba de atender demandas individuales que, por lo general, ponían de manifiesto fallos coyunturales y fácilmente identificables de los sistemas domésticos de tutela, sino de fiscalizar la compatibilidad de disposiciones generales y líneas de desarrollo político con el CEDH y la jurisprudencia del $\mathrm{TEDH}^{30}$.

A lo que se acaba de decir, debe añadirse que el TEDH no tuvo que esperar, en realidad, para llevar a cabo controles de tipo constitucional a que llegaran los Estados del telón de acero. Mucho antes había llevado a cabo análisis de leyes u otras disposiciones generales para determinar si una vulneración concreta del CEDH se debía a una incorrecta aplicación de dichas normas o si, por contra, la contravención del estándar europeo se encontraba en la propia norma. Es cierto que el TEDH sigue reiterando que su función es la tutela individual de los derechos a través de controles in concreto y que, por tanto, los controles in abstracto quedan fueran de su competencia ${ }^{31}$. Sin embargo, diga lo que diga sobre el alcance formal de su control, no es extraño ver en las sentencias europeas escrutinios de compatibilidad que van más allá de la mera aplicación de una norma ${ }^{32}$, muy especialmente, a través de las sentencias piloto.

En efecto, un elemento clave para afirmar la tendencia constitucionalizadora del TEDH es el procedimiento de caso piloto ${ }^{33}$. Los casos piloto suponen la formalización del control in

28 Liretalmente «purely intrumental role of the issue of «constitutionalisation», SADURSKI, W., «Partnering with Strasbourg...», op. cit., p. 400.

29 Cfr. Sadurski, W., «Partnering with Strasbourg...», op. cit., p. 422.

30 Vid. in extenso SADURSKI, W., «Partnering with Strasbourg...», op. cit., especialmente pp. 402-403 y 406 y ss.

31 No merece la pena ahora detenerse en esta cuestión a la que he tenido oportunidad de referirme con detalle en otros trabajos; me remito a Queralt Jiménez, A., La interpretación de los derechos : del Tribunal de Estrasburgo al Tribunal Constitucional, Centro de Estudios Políticos y Constitucionales, Madrid, 2008, pp. 54 y ss.

32 En esta misma línea recordaba GARLICKI, L. en «Contrôle de constitutionnalité et contrôle de conventionalité. Sur le dialigue des juges», en VVAA, Mélanges en l'honneur de Jean-Paul Costa, 2011, Daloz, Paris, pp. 272 y 273, como el TEDH se había visto obligado a llevar a cabo controles en concreto, como mínimo, en tres supuestos: en demandas entre Estados, en supuestos en los que la violación del CEDH emana directamente de una ley o disposición general o, incluso, cuando la violación deriva de un acto de ejecución de una disposición que contraviene el convenio.

33 Claramente lo señala SAdurski, W., «Partnering with Strasbourg...», op. cit.: es una de las bases de su texto. 
abstracto del TEDH respecto de los ordenamientos jurídicos internos, y ello sin que se haya producido ningún cambio normativo convencional. Todo sigue igual en el texto del Convenio, ya que el procedimiento del caso piloto es un método «adoptado» por el TEDH y normativizado en su reglamento, y empujado, como veremos, por las propias instituciones del Consejo de Europa, especialmente el Comité de Ministros. Por ello, en palabras de Sadurski ${ }^{34}$ :

«[...] the court can now announce that it is authorised (even compelled) to identify systemic defects in a legal system and to prescribe major legislative changes, its self-perception as a 'constitutional'court of sorts is quite clear.»

\section{LA APARICIÓN DE LAS SENTENCIAS PILOTO}

\section{Los casos piloto: causa y origen}

El procedimiento de caso piloto nace como respuesta a lo que el TEDH denomina demandas repetitivas. Son demandas individuales presentadas por personas no organizadas pero generadas por la misma causa, con el mismo origen. Por lo general, además, la causa de la violación suele estar en una disposición general interna (leyes, reglamentos, etc.) o en un fallo estructural del sistema nacional de tutela de los derechos, por acción u omisión.

Aunque el procedimiento piloto no fue codificado en el Reglamento del TEDH hasta 2011, el pistoletazo de salida de este método para lidiar con asuntos repetitivos lo dio el Comité de Ministros con la aprobación de la Resolución Res(2004)3 sobre sentencias que pongan de manifiesto problemas estructurales ${ }^{35}$. En esta resolución el comité invitaba al TEDH a que:

«i. As far as possible, to identify, in its judgments finding a violation of the convention, what it considers to be an underlying systemic problem and the source of this problem, in particular when it is likely to give rise to numerous applications, so as to assist states in finding the appropriate solution and the committee of ministers in supervising the execution of judgments;

ii. To specially notify any judgment containing indications of the existence of a systemic problem and of the source of this problem not only to the state concerned and to the committee of ministers, but also to the parliamentary assembly, to the secretary general of the council of Europe and to the Council of Europe commissioner for human rights, and to highlight such judgments in an appropriate manner in the database of the court»

En la misma sesión del Comité de Ministros, se aprobó, también, la Recomendación $\operatorname{Rec}(2004) 6^{36}$, que suponía la correspondiente traslación de su petición al TEDH en

34 SADURSKI, W., «Partnering with Strasbourg...», op. cit., p. 422.

35 Resolution Res(2004)3 of the Committee of Ministers on judgments revealing an underlying systemic problem (adopted by the Committee of Ministers on 12 May 2004, at its 114th Session).

36 Recommendation $\operatorname{Rec}(2004) 6$ of the Committee of Ministers to member states on the improvement of domestic remedies (adopted by the Committee of Ministers on 12 May 2004, at its 114th Session) 
sugerencias a los Estados. Así, les recordaba insistentemente que ellos son los primeros responsables de la tutela de los derechos convencionales (art. 1 CEDH) y que, además, según se desprende del art. $46 \mathrm{CEDH}$, deben cumplir con las sentencias dictadas contra ellos, siendo especialmente importante un rápido cumplimiento en los casos en los que se ha detectado un fallo estructural del sistema. En estos supuestos en los que la problemática interna pueda generar la llegada constante de demandas ante el TEDH, los Estados deben ser especialmente diligentes. De hecho, en el apéndice de esta recomendación dedicado a recoger una guía de buenas prácticas en relación con el cumplimiento de las sentencias del TEDH, el Comité de Ministros era bastante ambicioso con sus peticiones a los Estados, sobre todo, en el apartado relativo a los casos piloto. Y ello porque, como el órgano de supervisión reiteraba en este texto, las demandas repetitivas ${ }^{37}$ ponen en jaque al sistema. Así, cuando el TEDH identifica un problema estructural y declara que es este el origen de vulneración del CEDH, las autoridades domésticas deben asegurarse de que los potenciales solicitantes tengan, cuando corresponda, un recurso efectivo que les permita presentar una solicitud ante un tribunal competente interno, evitando así que el caso llegue ante el TEDH y respetando el principio de subsidiariedad del sistema europeo. De la implementación de dicho recurso efectivo depende, dice literalmente el Comité de Ministros, la reducción sustancial de la carga de trabajo del Tribunal. En este contexto, el Comité de Ministros,

«Recommends that member states, taking into account the examples of good practice appearing in the appendix:

I. Ascertain, through constant review, in the light of case-law of the court, that domestic remedies exist for anyone with an arguable complaint of a violation of the convention, and that these remedies are eective, in that they can result in a decision on the merits of the complaint and adequate redress for any violation found;

II. Review, following court judgments which point to structural or general deficiencies in national law or practice, the efectiveness of the existing domestic remedies and, where necessary, set up efective remedies, in order to avoid repetitive cases being brought before the court.»

Como se observa, el Comité abría una nueva etapa en la jurisprudencia del TEDH, incluso en la propia naturaleza de sus sentencias, dado que, en contra de lo que venía siendo la tónica general, inducía al Tribunal a identificar casos de violaciones con origen estructural y, lo más importante, a ayudar a determinar las medidas necesarias para ponerles remedio, tanto individuales como generales. Se iniciaba un cambio en el contenido y alcance de las decisiones de la jurisdicción europea, superando los estrechos límites en que se venía moviendo, al menos formalmente: mera declaración de vulneración del CEDH y, en su caso, concesión de una satisfacción equitativa. Esta Resolución abría la puerta y legitimaba una nueva etapa del sistema europeo hacia el control de disposiciones o medidas generales de los Estados parte, quedando el control concreto superado en este tipo de supuestos.

Asimismo, la semilla de los casos pilotos estaba plantada: el TEDH debía identificar aquellas demandas que tuvieran origen en fallos estructurales de los sistemas de protección internos que hubieran dado lugar o pudieran dar lugar a demandas repetitivas.

37 Vid más arriba. 
El Tribunal rápidamente hizo uso de la oportunidad abierta por el Comité de Ministros y la Gran Sala dictaba su primera sentencia piloto el 28 de septiembre de 2005, STEDH caso Broniowski contra Polonia. Este asunto, relativo al derecho a la propiedad privada reconocida en el Protocolo núm. 1 al CEDH, afectaba a unas 80.000 personas. En junio de 2004 la Gran Sala dictó una sentencia ${ }^{38}$ en la que se hacía constar el fallo estructural en la protección del derecho a la propiedad. En el fallo, el Tribunal declaraba que el derecho a la propiedad privada reconocido en el art. 1 del Protocolo núm. 1 al CEDH tenía su origen en un problema sistémico conectado con el malfuncionamiento de la legislación y prácticas internas, causado por la falta de un mecanismo efectivo que hiciera posible a los afectados reclamar la correspondiente indemnización. En consecuencia, el TEDH declaraba que Polonia debía (must) asegurar el ejercicio del derecho a la propiedad privada a través de la implementación de las correspondientes medidas legales y administrativas.

Tras la sentencia, el Parlamento polaco inició la tramitación de una nueva ley, aprobada en julio de 2005, que satisfacía los criterios establecidos por la Gran Sala en la sentencia de 2004. Con posterioridad, se alcanzó un acuerdo amistoso (art. 39 CEDH) relativo a la satisfacción equitativa (art. $41 \mathrm{CEDH})$ que sería reconocida a las víctimas de la violación del derecho a la propiedad. Este acuerdo fue recogido en la sentencia de archivo de la demanda de 28 de septiembre de 2005 de la Gran Sala. Fue en esta sentencia en la que el Tribunal inició formalmente la utilización del procedimiento de caso piloto, al amparo de la Resolución del Comité de Ministros de 2004 y en aplicación del art. $46 \mathrm{CEDH}$ :

«The object in designating the principal judgment as a «pilot judgment» was to facilitate the most speedy and effective resolution of a dysfunction affecting the protection of the right of property in the national - polish - legal order. One of the relevant factors considered by the court was the growing threat to the convention system and to the court's ability to handle its ever increasing caseload that resulted from large numbers of repetitive cases deriving from, among other things, the same structural or systemic problem (see Broniowski, cited above). Indeed, the pilot judgment procedure is primarily designed to assist the contracting states in fulfilling their role in the convention system by resolving such problems at national level, thereby securing to the persons concerned the convention rights and freedoms as required by article 1 of the convention, offering to them more rapid redress and, at the same time, easing the burden on the court which would otherwise have to take to judgment large numbers of applications similar in substance. It will be recalled that, in the pilot judgment in Mr. Broniowski's application, the court, after finding a violation, also adjourned its consideration of applications deriving from the same general cause «pending the implementation of the relevant general measures» ${ }^{39}$.

En esta decisión, el TEDH avaló el acuerdo alcanzado por el Sr. Broniowski y el Gobierno polaco — en tanto que incorporaba medidas individuales dirigidas a compensar al demandante, pero, también, medidas de carácter general que pudieran ser aplicadas a todas aquellas personas que se encontraran en la misma situación que Broniowski. Así, como el propio Tribunal señalaba, se tutelaba el derecho individual del demandante a la

38 Asunto Broniowski contra Polonia, de 22 de junio de 2004.

39 Pár. 35 STEDH Broniowski de 28 de septiembre de 2005. 
vez que preservaba la subsidiariedad del sistema europeo dejando en manos del Estado polaco la protección del derecho a la propiedad privada de los demás afectados.

El cumplimiento de las medidas generales e individuales a las que se comprometió el Gobierno polaco en el acuerdo amistoso fue verificado por el Comité de Ministros. De hecho, en su resolución final del caso en $2009^{40}$, testaba la adecuación y suficiencia de las medidas adoptadas mediante dos decisiones de inadmisibilidad del TEDH en varios casos con el mismo fondo que Broniowski ${ }^{41}$. En estas decisiones el Tribunal afirmaba que:

«For that reason, the Court's findings in the present case as to whether the enactment of the July 2005 Act and its operation in practice «secure[d] the implementation of the property right in question in respect of the remaining Bug River claimants..., in accordance with the principles of protection of property rights under Article 1 of Protocol No. 1» and whether, in consequence, the «matter has been resolved» for the purposes of Article $37 \S 1$ (b) will be valid in the context of all subsequent similar cases» ${ }^{42}$.

Finalmente, en $2011^{43}$ entró en vigor una nueva reforma del Reglamento del $\mathrm{TEDH}^{44}$, por la que se incorporó el procedimiento de sentencia piloto. Con este procedimiento pretendía dotarse al sistema de un medio para tratar con grandes bolsas de casos idénticos con el mismo origen (demandas repetitivas).

A grandes rasgos, el funcionamiento del procedimiento es el siguiente: cuando el Tribunal recibe un número significativo de demandas que se deriven de la misma causa, podrá decidir seleccionar una o varias de ellas y darles una tramitación prioritaria. Al estudiar el caso o casos seleccionados, tratará de lograrse una solución que pueda extenderse más allá del caso o casos estudiados, de modo que abarque todos los asuntos similares, esto es, que plantean el mismo problema de base, tanto presentes como futuros.

En todo caso, son varias las finalidades de este procedimiento. La primera está clara: dar solución a problemas estructurales de un Estado, lo que, a su vez, deber evitar la llegada de nuevas demandas ante el $\mathrm{TEDH}^{45}$. Asimismo, según el Tribunal, este procedimiento favorece una reparación más rápida de la violación (o violaciones) del Convenio. También se persigue otro objetivo importante desde la perspectiva del sistema: este procedimiento permite aumentar la productividad del Tribunal ${ }^{46}$. Por último, en la base de

40 Final Resolution CM/ResDH(2009)89, adoptada por el Comité de Ministros de 30 de septiembre de 2009.

41 Decisión en el caso Wolkenberg y otros contra Polonia, de 4 de diciembre de 2007, y decisión en el caso Witkowska-Tobola contra Polonia, también de 4 de diciembre de 2007.

42 Pár. 36 Wolkenberg y otros contra Polonia.

43 Desde la STEDH en Broniowski hasta la aprobación de la reforma del Reglamento del TEDH en 2011, el Tribunal utilizó como base para utilizar el procedimiento de casos pilotos su sentencia de 2005, lo que hizo por segunda vez en la STEDH Hutten-Czapska contra Polonia, de 22 de febrero de 2005, sentencia de Sala. En este supuesto se repitió el mismo esquema: sentencia de Sala, sentencia de Gran Sala confirmando la decisión de la Sala y segunda sentencia de Gran Sala recogiendo un acuerdo amistoso con medidas individuales y medidas generales.

44 Incorporado por el TEDH el 21 de febrero de 2011.

45 Di Marco A., «L'État face aux arrêts pilotes de la Cour Européenne Des Droits de l'Homme,» en Revue trimestrielle des droits de l'homme, núm. 108, p. 888.

46 Estos dos elementos son señalados por el TEDH en la Factsheet relativa a las sentencias piloto, actualizada en febrero de 2018, https://www.echr.coe.int/Documents/FS_Pilot_judgments_ENG.pdf (consultada el 15 de julio de 2018). 
este procedimiento está recuperar la subsidiariedad de la tutela que ofrece el sistema procurando al Estado la guía necesaria para que adopte en el ámbito interno los instrumentos efectivos para poner remedio a la vulneración detectada ${ }^{47}$.

\section{El art. 61 RTEDH: base normativa de las sentencias piloto}

El art. 61 fue incorporado en febrero de 2011 al Reglamento del TEDH. Es un artículo largo y prolijo al que merece la pena echar, si quiera, un breve vistazo ya que en él se establecen las bases normativas sobre las que funciona el TEDH a la hora de utilizar el procedimiento de caso piloto.

En primer lugar, las normas de funcionamiento del Tribunal fijan el objeto de los casos piloto: asuntos en los que los hechos revelen la existencia de un fallo estructural o sistémico u otra disfunción similar que haya dado lugar o pueda dar lugar a aplicaciones similares.

La adopción del método de caso piloto será siempre de oficio, pero las partes pueden solicitarlo. En todo caso, antes de decidir que a la demanda le será aplicado el procedimiento de caso piloto, el Tribunal recabará la opinión de las partes sobre la existencia de un problema o disfunción en el Estado demandado y sobre la idoneidad de tramitar la demanda como piloto. Una vez decidido que el asunto será piloto, su tramitación tendrá carácter prioritario ${ }^{48}$.

En su sentencia piloto, el Tribunal identificará tanto la naturaleza estructural o sistemática del problema o disfunción, así como el tipo de medidas reparadoras que el Estado demandado deberá adoptar en el ámbito nacional en virtud del fallo de la sentencia. En el fallo, además, el Tribunal podrá determinar en qué plazo deben adoptarse aquellas medidas, teniendo en cuenta su naturaleza y la rapidez con la que puedan ser adoptadas.

Por último, el art. 61 del RTEDH se refiere a los efectos que genera una sentencia piloto tanto respecto de los demandantes en el supuesto estudiado como respecto del resto de demandas presentadas ante el Tribunal por la misma causa. Así, en primer lugar, el Reglamento señala que al adoptar una sentencia piloto, el Tribunal podrá reservarse la cuestión de la satisfacción equitativa en su totalidad o en parte a la espera de la adopción por el Estado responsable de las medidas individuales y generales fijadas en la sentencia.

En cuanto a los casos similares, el Tribunal puede decidir aplazar su examen a la adopción de las medidas reparadoras requeridas en su decisión. En este caso, se informará adecuadamente a los demandantes del aplazamiento del estudio de sus recursos y serán notificados de todas las vicisitudes del proceso que también afecten a su causa. En cualquier caso, el Tribunal podrá recuperar el estudio de una demanda aplazada cuando el interés de la justicia así lo exija. Asimismo, si pasado el plazo, el Estado infractor no

47 STEDH caso Ananyev y otros contra Rusia, de 10 de enero de 2012, pár. 182. Este párrafo se repite prácticamente en todas las sentencias piloto del TEDH; entre las más recientes, asunto Rezmives y otros contra Rumania, de 25 de julio de 2017, pár. 104.

48 Los criterios de priorización del TEDH pueden consultarse en https://www.echr.coe.int/Documents/Priority_policy_ENG.pdf (consultado el 15 de julio de 2018). 
cumple con las medidas acordadas en la sentencia piloto, el Tribunal podrá recuperar la tramitación de las demandas previamente aplazadas.

Es importante señalar que las sentencias piloto son tomadas por el Tribunal como un instrumento que atañe a todo el sistema europeo de garantía y, por ello, cuando dicta una de estas sentencias da cuenta de ello al Comité de Ministros, a la Asamblea Parlamentaria del Consejo de Europa, el Secretario General del Consejo de Europa, y al Comisario para los Derechos Humanos del Consejo de Europa. De esta forma pretende ponerse el acento sobre la base estructural de la vulneración del Convenio, elemento que necesita, en muchas ocasiones, de la concurrencia de diferentes actores para su reversión.

\section{PRÁCTICA Y ALCANCE DE LAS SENTENCIAS PILOTO}

\section{La decisión de aplicar el procedimiento de caso piloto}

La decisión de identificar una sentencia como piloto y la aplicación de los elementos establecidos en el art. $61 \mathrm{RTEDH}$ se hace en virtud del art. $46 \mathrm{CEDH}$. Así, después de analizar las vulneraciones materiales del $\mathrm{CEDH}$, a veces incluso después de hacer el examen sobre la necesidad de reconocer una satisfacción equitativa a los demandantes (art. $41 \mathrm{CEDH}$ ), se abre, en la parte argumentativa de la sentencia, un epígrafe dedicado al art. $46 \mathrm{CEDH}$.

Ahora que el Tribunal cuenta ya con un cierto acervo jurisprudencial sobre sentencias piloto, en primer lugar, se recuerdan los principios generales que sustentan el procedimiento piloto y los elementos que lo caracterizan. En esta línea, en principio el supuesto habilitante viene marcado, como se ha visto, por el art. $61 \mathrm{CEDH}$ : cuando los hechos de una demanda revelen la existencia de un problema sistémico o estructural u otra disfunción que haya aparecido ya en diferentes asuntos. A partir de aquí, es competencia exclusiva del Tribunal decidir si en una demanda o supuesto de hecho concurren las situaciones descritas. A este respecto, las partes pueden indicar la necesidad de convertir el proceso en un procedimiento piloto. Sin embargo, no parece que quepa distinguir todavía un criterio inequívoco que permita anticipar, en todo caso, la decisión del TEDH al respecto. Esto es, el Tribunal, cuando adopta la decisión de aplicar el procedimiento piloto sí que identifica cual es el problema sistémico o disfunción, aunque tampoco se distingue entre problema estructural, sistemático o disfunción del sistema interno. Sin embargo, no conocemos todavía los elementos concretos que deben concurrir para que el Tribunal identifique una demanda como piloto respecto del resto de demandas similares, cuál es la razón que le lleva a preferir una demanda respecto de otras ${ }^{49}$.

49 Por ejemplo, en Mansur Yalçın y otros contra Turquía, de 16 de septiembre de 2014, relativo al art. 2 Protocolo 1 al CEDH: en este supuesto, el Tribunal trataba, de nuevo, la forma en que se dan las clases de religión y ética en los cursos de primaria y secundaria y el respeto las convicciones religiosas y morales de los padres. En este caso, el Tribunal, al analizar el alcance de las obligaciones del art. $46 \mathrm{CEDH}$, afirmaba que esta vulneración derivaba de un problema estructural y que, por ello, el Estado debía seguir las directrices sentadas en párrafos previos de la sentencia, que reiteraban, además, lo ya dicho en STEDH Hasan and Eylem Zengin contra Turquía, de 9 de octubre de 2007, sentencia que tampoco fue calificada como piloto. Como se observa, pese a la detección como problema estructural, no se utiliza el sistema de procedimiento piloto. Cfr. GLAS, L. «The Functioning of the Pilot-Judgment Procedure of the European Court of Human Rights in Practice,» March 16, 2016, https://papers.ssrn.com/sol3/ 
El problema puede ser identificado en el primer asunto sobre la materia respecto del que el TEDH dicte una sentencia (Bronioswki y otros), siempre y cuando haya sido advertida la llegada a Estrasburgo de una cantidad importante de demandas con la misma básica fáctica.

A veces, en cambio, un lapso menor de tiempo y un volumen también menor de condenas previas, pueden determinar que el Tribunal adopte el procedimiento piloto. Así ocurrió, por ejemplo, en el asunto W. D. contra Bélgica, de 6 de septiembre de 2016, declarada sentencia piloto en relación con el problema estructural que supone que en las prisiones belgas los internos no cuenten con tratamiento psiquiátrico adecuado a sus patologías mentales, lo que contraviene los art. 3 y 5 del CEDH. Según el Tribunal desde el caso L.B. contra Bélgica, de 22 de octubre de 2012, las demandas presentadas sobre la base de las mismas violaciones del CEDH no habían hecho más que $\operatorname{crecer}^{50}$, aunque no habían sido más de 20 sentencias dictadas. En todo caso, aunque este número puede parecer escaso en comparación con el volumen de asuntos similares necesarios para activar el procedimiento piloto en otros supuestos, como se verá enseguida, el Tribunal acompañó su decisión de los informes elaborados por otras organizaciones nacionales e internacionales centradas en la garantía de los derechos de los presos ${ }^{51}$. La razón última, en este caso, parecía ser el número de personas a las que potencialmente podía afectar el problema estructural señalado ${ }^{52}$. La subsidiariedad y la efectividad del sistema europeo estaban en la base de las razones expuestas.

En otras ocasiones, en cambio, el TEDH puede tardar años en tomar la decisión de adoptar un caso piloto. Cabe poner como ejemplo el caso de las dilaciones indebidas, incluso incumplimientos, en la ejecución de resoluciones judiciales en Ucrania. En 2004, el Tribunal dictó sentencia en varios asuntos en los que ya se ponía de manifiesto esta situación ${ }^{53}$. Pese a ello, el número de demandas europeas sobre el mismo motivo no dejaba de crecer. Tanto es así que son varios los documentos que ha ido elaborando el Comité de Ministros en su labor de supervisión de estos asuntos ${ }^{54}$. Pasados unos años, el Tribunal dictó la sentencia en el caso Yuriy Nikolayevich Ivanov contra Ucrania, de 15 de octubre de 2009, en la que se ponía de manifiesto las reiteradas llamadas de atención que pesaban sobre este Estado en esta materia: las más de 300 sentencias dictada contra Ucrania desde 2004 a $2009^{55}$ sobre incumplimiento o dilaciones injustificadas en la ejecución judicial, los más de 1400 casos pendientes ante las formaciones del Tribunal ${ }^{56}$, y las recurrentes decisiones del Comité de Ministros sobre esta materia (en diciembre de 2009 eran

papers.cfm?abstract_id=2748540, p. 4; HaIDER, D., The Pilot-Judgement Procedure of the European Court of Human Rights, Martinus Nijhoff Publishers, Países Bajos, 2013.

50 En el momento de dictarse esta sentencia, había pendientes unas 40 demandas con la misma motivación.

51 Vid. pár. 71 y ss. de la STEDH W. D. contra Bélgica.

52 Pár. 166. de 2004

53 Se toma como referencia la STEDH caso Zhovner (y otros casos similares) contra Ucrania de 26 de junio

54 Destaca el documento informativo «Non-enforcement of domestic judicial decisions in Ukraine: general measures to comply with the European Court's judgments. Memorandum prepared by the Department for the Execution of the judgments of the European Court (Application of Article 46 of the ECHR), CM/Inf/DH(2007)30-rev, de 13 de junio de 2007 (https://search.coe.int/cm/Pages/result_details.aspx?ObjectID=09000016805ad2b9), (consultado el 15 de julio de 2018).

55 STEDH caso Ivanov pár. 83.

56 STEDH caso Ivanov pár. 86. 
324 las sentencias del TEDH contra Ucrania en fase de ejecución $)^{57}$. Estos elementos fueron los que llevaron al Tribunal a declarar el asunto Ivanov como caso piloto ${ }^{58}$.

Este procedimiento piloto, sin embargo, no tuvo los frutos esperados dado que, como se verá más adelante en relación con la relevante STEDH de Gran Sala en Burmych y otros contra Ucrania (archivo) de 12 de octubre de 2017, el sistema no ha logrado todavía que Ucrania adopte las medidas individuales y generales necesarias para dar por cumplidas sus obligaciones.

\section{Tipo de control y naturaleza de las sentencias piloto}

Las sentencias piloto, como se viene diciendo desde el principio, suponen un cambio respecto del control que realiza el Tribunal cuando resuelve una demanda y respecto de la naturaleza de sus sentencias. Según jurisprudencia absolutamente reiterada y consolidada del TEDH, la función de tutela individual que tiene atribuida el Tribunal como órgano de control del cumplimiento de los derechos convencionales se lleva a cabo a través de un control concreto de las demandas, una tutela caso a caso. Esto supone, en principio, que el Tribunal cuando examina una demanda individual contra un Estado parte se limita a comprobar si los hechos descritos, actos o ejecuciones de normas generales, son contrarios al estándar europeo. Tal y como se ha dicho más arriba, el Tribunal ha reiterado que su naturaleza internacional y subsidiaria no le permite realizar controles en abstracto de los ordenamientos jurídicos implicados. Sin embargo, es igualmente conocido que el Tribunal en no pocas ocasiones ha excepcionado su propia regla, haciendo controles in abstracto de normas o disposiciones generales. Insisto, es cierto, que estas ocasiones han sido consideradas como excepciones a la norma general de funcionamiento ${ }^{59}$. Sin embargo, en el procedimiento piloto la naturaleza del control cambia totalmente ya que su razón de ser es la necesidad de llevar a cabo un control general de la situación de la que derivan muchas (decenas, cientos o miles) de vulneraciones convencionales. Una parte importante de la sentencia se dedica, precisamente, a señalar cuales son las carencias del sistema doméstico y qué tipo de medidas deberían ser adoptadas.

El segundo gran cambio que se apuntaba se produce en relación con la naturaleza de las sentencias europeas. Es muy relevante destacar la premisa de la que parte el TEDH para reclamar la adopción de medidas individuales y generales a los Estados. El Tribunal parte de su jurisprudencia sobre el alcance de la obligación del art. $46 \mathrm{CEDH}$, la restitutio

57 Cfr. Interim Resolution CM/ResDH(2009)159: Execution of the judgments of the European Court of Human Rights in 324 cases against Ukraine concerning the failure or serious delay in abiding by final domestic courts' decisions delivered against the state and its entities as well as the absence of an effective remedy, adoptada por el Comité de Ministros el 3 de deciembre de 2009 (https://search.coe.int/cm/Pages/result_details. aspx? ObjectID=09000016805ad6d5\#_ftn1).

58 La misma actuación desarrolló el TEDH en la saga de casos contra Rumanía. Así, en la STEDH Rezmives, y otros contra Rumanía, de 25 de abril de 2017, sobre la situación de los centros de detención y prisiones, el TEDH, además de explicar la implicación del propio Tribunal y del Comité de Ministros en el problema estructural ya detectado en casos anteriores, ofrecía los siguientes datos y cifras : a) el problema estructural fue identificado en una sentencia de 2012 (Iacov Stanciu contra Rumanía); b) más de 4 años después, el TEDH había dictado 150 sentencias declarativas de la violación del art. 3 CEDH por el mismo supuesto de hecho; c) en agosto de 2016, existía una bolsa de 3200 demandas pendientes sobre la misma cuestión ante las formaciones del TEDH.

59 Vid. Queralt Jiménez, A. La interpretación de los derechos, op.cit., 29 y ss. 
in integrum del demandante, recordando que ello implica también adoptar las mismas medidas respecto del resto de afectados por la vulneración. Se parte de una concepción muy amplia del compromiso de los Estados de velar por el respeto y garantía de los derechos y de cumplir con las sentencias del TEDH. La determinación del Tribunal es absoluta:

«The Court recalls that Article 46 of the Convention, as interpreted in the light of Article 1, imposes on the respondent State a legal obligation to implement, under the supervision of the Committee of Ministers, appropriate general and/or individual measures to secure the right of the applicant which the Court found to be violated. Such measures must also be taken in respect of other persons in the applicant's position, notably by solving the problems that have led to the Court's findings (...). This obligation has consistently been emphasised by the Committee of Ministers in the supervision of the execution of the Court's judgments (see, among many authorities, Interim Resolutions DH(97)336 in cases concerning the length of proceedings in Italy;... $)^{60}$.»

Las sentencias piloto son un instrumento a través del que Tribunal reivindica la obligatoriedad de sus decisiones y refuerza su alcance. Para cumplir con las sentencias del Tribunal, todas ellas, no solo las piloto, se requiere que los Estado adopten las medidas necesarias para restablecer al particular en sus derechos, para evitar que la vulneración del $\mathrm{CEDH}$ se repita y para permitir al resto de víctimas de la violación convencional disfrutar de los remedios efectivos brindados al demandante individual. Lejos queda esta aproximación de aquellas sentencias meramente declarativas.

Sentadas las bases del alcance de la obligatoriedad de sus decisiones, y a diferencia de lo que es la regla general en la práctica del Tribunal, en las sentencias de los casos piloto, además de identificar en la argumentación de la decisión cuales son las causas concretas que generan la disfunción interna, en el fallo se señala al Estado responsable de la violación que debe adoptar las medidas generales e individuales que sean necesarias para acabar con esta situación. Se rompe claramente con la naturaleza tradicional que se venía atribuyendo a las sentencias de Estrasburgo, derivada de su naturaleza internacional, y que esta jurisdicción había asumido: sentencias declarativas, cuyo fallo se limitaba a constatar, en su caso, la vulneración del CEDH y que podía venir acompañada de una decisión sobre la satisfacción equitativa para las víctimas. A continuación de reproduce una secuencia de extractos de la sentencia Torreggiani y otros contra Italia, en la que quedan reflejados los elementos a los que se acaba de hacer referencia: TEDH:

a) Margen de apreciación pero obligado cambio de alcance de las sentencias del

« La Cour rappelle que ses arrêts ont un caractère essentiellement déclaratoire et qu'il appartient en principe à l'État défendeur de choisir, sous le contrôle du Comité des Ministres, les moyens de s'acquitter de son obligation juridique au regard de l'article 46 de la Convention $»^{61}$.

60 STEDH caso Ananyev y otros contra Rusia, pár. 180. Esta fórmula es utilizada en todas las sentencias piloto.

61 Pár. 91. Cursiva añadida por la autora. 
« La Cour est consciente que des efforts conséquents et soutenus sur le long terme sont nécessaires pour résoudre le problème structurel du surpeuplement carcéral. Toutefois, elle rappelle qu'au vu du caractère intangible du droit protégé par l'article 3 de la Convention, l'État est tenu d'organiser ${ }^{62}$ son système pénitentiaire de telle sorte que la dignité des détenus soit respectée ».

b) El TEDH sugiere al Estado la adopción de medidas generales e individuales de distinto calado, aunque manteniendo una actitud muy deferente con dicho Estado,

« En particulier, [...] la Cour l'encourage à agir de sorte à réduire le nombre de personnes incarcérées, notamment en appliquant davantage des mesures punitives non privatives de liberté et en réduisant au minimum le recours à la détention provisoire ${ }^{63}$.

«Il n'appartient pas à la Cour d'indiquer aux États des dispositions concernant leurs politiques pénales et l'organisation de leur système pénitentiaire. Ces processus soulèvent un certain nombre de questions complexes d'ordre juridique et pratique qui, en principe, dépassent la fonction judiciaire de la Cour. Néanmoins, elle souhaite rappeler dans ce contexte... $[\ldots]^{64}$.

c) Pero sin hacer dejación de sus funciones de garante de los derechos del CEDH:

« En ce qui concerne la ou les voies de recours internes à adopter pour faire face au problème systémique reconnu dans la présente affaire, la Cour rappelle qu'en matière de conditions de détention, les remèdes " préventifs » et ceux de nature « compensatoire » doivent coexister de manière complémentaire ${ }^{65}$.

"La Cour n'a pas à préciser quelle serait la meilleure manière d'instaurer les voies de recours internes nécessaires. L'Etat peut soit modifier les recours existants soit en créer de nouveaux de sorte que les violations des droits tirés de la Convention puissent être redressées de manière réellement effective. Il lui incombe également, sous le contrôle du Comité des Ministres, de garantir que le recours ou les recours nouvellement mis en place respectent, tant en théorie qu'en pratique, les exigences de la Convention ${ }^{66}$.

«Elle en conclut que les autorités nationales doivent sans retard mettre en place un recours ou une combinaison de recours ayant des effets préventifs et compensatoires et garantissant réellement une réparation effective des violations de la Convention résultant du surpeuplement carcéral en Italie ${ }^{67}$.

d) Todo ello queda recogido en el fallo de la sentencia como una obligación de hacer del Estado que deberá, cumplir, además, en un plazo determinado:

« [...] Dit que l'État défendeur devra, dans un délai d'un an à compter de la date à laquelle le présent arrêt sera devenu définitif en vertu de l'article $44 \S 2$ de la Convention, mettre en place un recours ou un ensemble de recours internes effectifs aptes à offrir un

62 Pár. 93. Cursiva añadida por la autora.

63 Pár. 94.

64 Pár. 95. Cursiva añadida por la autora.

65 Pár. 96.

66 Pár. 98. Cursiva añadida por la autora.

67 Pár. 99. Cursiva añadida por la autora. 
redressement adéquat et suffisant dans les cas de surpeuplement carcéral, et ce conformément aux principes de la Convention tels qu'établis dans la jurisprudence de la Cour ${ }^{68}$.

Las sentencias piloto implican reconocer un alcance máximo a la obligatoriedad de las sentencias del TEDH, partiendo del reconocimiento de las dos premisas tradicionales del sistema: los destinatarios primeros y naturales de la obligación de respetar y garantizar los derechos y libertades convencionales son los Estados. Para la consecución de esta obligación jurídica de resultado los Estados cuentan con libertad para elegir los medios que utilizan. Ahora bien, como el TEDH lleva advirtiendo claramente desde Papamichalopuolus contra Grecia (1995), dicho margen de apreciación no es ilimitado y no puede, en ningún caso, suponer el menoscabo del estándar europeo ni tampoco poner en riesgo el sistema de garantía europeo.

\section{Las demandas similares}

Cuando el Tribunal decide identificar un caso como piloto, ¿qué ocurre con las demandas ya interpuestas y que basan la violación del CEDH en el mismo fallo del sistema estatal que la decisión de marras? De nuevo, la subsidiariedad y la propia supervivencia del sistema europeo se imponen sobre la tutela individual de todas y cada una de las demandas que llegan a Estrasburgo, aunque, en principio, superen los criterios de admisibilidad del art. $35 \mathrm{CEDH}$.

Por lo general el Tribunal diferencia entre las demandas que han sido comunicadas al Estado infractor con anterioridad a la sentencia piloto, a las que «congela» (pospone su estudio) e intenta que su tutela sea «repatriada», como describe G. Cano Palomares ${ }^{69}$. Esto significa que, en la sentencia piloto, el TEDH suele exigir al Estado que permita a los demandantes en Estrasburgo que interpusieron su demanda previamente a la sentencia piloto utilizar retroactivamente los recursos efectivos que se generen en cumplimiento de la decisión europea. En el caso de que pasado el plazo señalado por el Tribunal para implementar las medidas y para compensar a los afectados aquellas no se hayan adoptado, el Tribunal podrá retomar el estudio de las demandas «congeladas» previamente. En cambio, si las medidas internas son adoptadas, en principio, el Tribunal iniciará la inadmisión de demandas con el mismo fondo y archivará las que estuvieran pendientes.

Así lo hizo en Burdov contra Rusia (2), de 15 de enero de 2009, en la que diferenció entre las demandas que ya habían sido interpuestas y comunicadas al Estado de las que pudieran interponerse a partir del momento en que se dictara la sentencia. Respecto de un problema estructural por el que los particulares no conseguían que se ejecutaran las sentencias que acreditaban deudas generadas por el Estado (art. $6 \mathrm{CEDH})$, los demandantes

68 Fallo, pár. 4. Cursiva añadida por la autora.

Esta misma estructura, identificación y explicación en los fundamentos jurídicos y concreción en el fallo, se repite en todos los asuntos piloto, por ejemplo, STEDH Varga y otros contra Hungría, de 10 de marzo de 2015 (contravención del art. 3 CEDH debido a la masificación de las prisiones); también en la ya citada STEDH Rezmiveș y otros contra Rumanía; STEDH W.D. contra Bélgica citada más arriba, o, STEDH Gazsó contra Hungría, de 16 de julio de 2015.

69 Vid. Saavedra Alessandri, P., Cano Palomares, G. y Hernández Ramos, M. «Repración y Supervisión de Sentencias,» in García Roca, J., y Carmona Cuenca, E. ¿Hacia una globalización de los derechos?, Aranzadi, Cizur Menor, 2017, p. 227. 
de los casos ya comunicados deberían beneficiarse de las mismas condiciones y plazo, un año, del mecanismo de compensación por inejecución que implementara Rusia en cumplimiento de Burdov. Se excluye, eso sí, la satisfacción equitativa que fija el TEDH en virtud del art. 41. CEDH. El resto de las demandas serían «congeladas» durante un año ${ }^{70}$.

Esta misma medida diferenciadora se aplicó en Gerasimov y otros contra Rusia, de 1 de julio de 2014, también como respuesta a la falta de un remedio efectivo interno (art. 13 $\mathrm{CEDH}$ ) para hacer ejecutar determinados tipos de sentencias en contra del Estado. En este supuesto, se daba un año a Rusia para implementar los remedios efectivos y dos para que los demandantes en Gerasimov y los de las demás demandas comunicadas recibieran el correspondiente restablecimiento interno.

En otras ocasiones, el Tribunal ha decidido continuar admitiendo demandas durante el plazo otorgado para adoptar las medidas de carácter general por el Estado. Así, lo hizo, por ejemplo, en la sentencia Dimitrov y Hamanov contra Bulgaraia, de 11 de mayo de 2011, sobre dilaciones excesivas en los procedimientos penales y civiles sin que existieran mecanismos efectivos para revertir o compensar esta situación, art. 6 y 13 CEDH. Solo adoptadas las medidas generales necesarias, y mostrada su efectividad, el TEDH ha decidido inadmitir demandas similares ${ }^{71}$.

Llama la atención, en cambio, que en sentencias piloto dictadas respecto de fallos sistémicos que entrañan violaciones del art. $3 \mathrm{CEDH}$, el Tribunal no haya optado por la misma solución, esto es, admitir demandas en tanto el Estado infractor no adoptada las medidas señaladas en Estrasburgo. Un ejemplo claro es Torreggiani y otros contra Italia, relativo al nivel de masificación de las prisiones italianas, donde el TEDH decidió congelar durante un año, plazo otorgado para implementar los remedios efectivos, las demandas no comunicadas en el momento de dictar la sentencia piloto. La misma decisión adoptó respecto de las demandas ya comunicadas en casos similares al ventilado en la sentencia W.D. contra Bélgica, de 6 de septiembre de 2019 y en Rezmiveș y otros contra Rumanía, de 25 de abril de 2017.

Esta decisión es especialmente sorprendente sabiendo que en otras sentencias piloto en las que el Tribunal consideró vulnerado el art. $3 \mathrm{CEDH}$ por la situación de hacinamiento en los centros de prisión provisional o en cárceles ordinarias, su respuesta fue seguir admitiendo demandas y no posponer las demandas ya comunicadas, en primer lugar:

«Having regard to the fundamental nature of the right protected by Article 3 of the Convention and the importance and urgency of complaints about inbuman or degrading treatment ${ }^{72}$, the Court does not consider it appropriate to adjourn the examination of similar cases» (pár. 239)

Y además, porque

«the Court observes that continuing to process all conditions-of-detention cases in a diligent manner will remind the respondent State on a regular basis of its obligations under the Convention and in particular those resulting from this judgment ${ }^{73}$

70 Pár. 7 y 8 del fallo respectivamente.

71 Decisiones de inadmisibilidad de 18 de junio de 2013, en asuntos Valcheva y Abrashev contra Bulgaria; Balakchiev y otros contra Bulgaria.

72 Cursiva añadida por la autora.

73 Cursiva añadida por la autora. 
Así, el TEDH decide seguir tramitando casos similares dada la gravedad de las violaciones generadas por las malas condiciones en los centros penitenciarios y como instrumento de presión sobre el Estado.

En cualquier caso, cuando el Tribunal decide posponer la tramitación de los asuntos ya comunicados al Estado, se establece un plazo y, además, se le indica que el restablecimiento de los derechos puede producirse a través de soluciones ad hoc, por ejemplo, a través de acuerdos amistosos o declaraciones unilaterales de mejora y/o compensación del Estado ${ }^{74}$ que, por supuesto, el TEDH deberá validar. En esta línea se pronunció el Tribunal en Ananyev y otros contra Rusia, de 10 de enero de 2012, también en Neshkov y otros contra Bulgaria, 27 de enero de 2015, Varga and Others v. Hungary, de 10 de marzo de 2015.

\section{Efectividad de las sentencias piloto}

Por último, debe hacerse una valoración sobre la efectividad de las sentencias piloto, incluida también su ejecución ya que su correcto cumplimiento determinará su efectividad.

Como ya se ha dicho, puede suceder que algunas demandas sean congeladas, mientras que otras serán inadmitidas durante el transcurso del plazo otorgado al Estado para adoptar las medidas individuales y generales necesarias.

El TEDH no ha aprovechado el procedimiento piloto para hacerse suya la supervisión de la ejecución de sus sentencias. Es cierto que el Tribunal se ha adentrado en la identificación de medidas, al menos el tipo de medidas, a adoptar por el Estado para dar cumplimiento a este tipo de sentencias. Lo ha hecho respecto de la adopción de medidas individuales más allá del reconocimiento de la satisfacción equitativa del demandante o demandantes del caso elegido como piloto. Y también respecto del señalamiento de las medidas generales: medidas normativas ${ }^{75}$, preventivas $^{76}$, compensatorias $^{77}$, modelos de reparación ${ }^{78}$, entre otras. Sin embargo, el Tribunal insiste en que esta transformación de la naturaleza de sus juicios no altera la competencia del Comité de Ministros que, a través de los procedimientos de supervisión adecuados, debe procurar y verificar que se adoptan las medidas apuntadas y acordadas con el Gobierno en el plazo establecido por el Tribunal.

Así, el Tribunal, una vez superado el plazo de implementación de las medidas que permitan a los particulares tutelar su derecho de forma efectiva ante las instancias nacionales, a la hora de examinar nuevas demandas con la misma base fáctica no entra a valorar en detalle la o las medidas adoptadas por los Estados. En general, si haciendo un análisis superficial de las novedades internas puede entender que se cumplen los estándares mínimos exigidos por el Convenio, inadmitirá la demanda por considerar que no se han agotado los (nuevos) mecanismos internos ${ }^{79}$. Dicho de otra forma, en

74 Está opción fue incorporada en el art. 62A del RTEDH en una modificación de 2 de abril de 2012.

75 STEDH W.D. contra Bélgica de 6 de septiembre de 2016.

76 STEDH Gazsó contra Hungría, de 16 de julio de 2015.

77 STEDH Gazsó contra Hungría, de 16 de julio de 2015.

78 STEDH Kurić y otros contra Eslovenia, de 26 de junio de 2012, de Gran Sala.

79 Por ejemplo, decisión de inadmisibilidad del caso Domján contra Hungría, de 23 de noviembre de 2017. El TEDH inadmitió la demanda, basada en los mismos hechos que la sentencia piloto dictada en Varga y otros 
general, se presume la efectividad de los instrumentos adoptados bajo la supervisión del Comité de Ministros. De esta forma se refuerza la idea de que son los Estados los primeros responsables de velar por el respeto y garantía de los derechos reconocidos en el CEDH, afianzando la subsidiariedad del sistema. Además, se respeta la distribución de funciones entre el TEDH y el Comité que, como se acaba de mencionar, no se ve afectada por el procedimiento piloto.

En esta línea, el Tribunal ha iniciado una práctica por la que cuando observa que le llegan nuevas demandas contra un Estado basadas en un fallo sistémico o malfuncionamiento sobre el que ya ha dictado una sentencia piloto, inadmite las demandas y las reconduce al ámbito de la ejecución de sentencias en manos del Comité. Esta forma de actuar responde, primero, a la necesidad de quitarse de encima demandas relativas a violaciones sobre las que ya hay una decisión de fondo y, segundo, a entender que si hay nuevas demandas es porque alguna cosa está fallando en la fase de supervisión de cumplimiento de las sentencias, y, por tanto, cae bajo la competencia del Comité de Ministros.

El cumplimiento de las medidas, sobre todo las generales, no siempre se produce en el plazo marcado por el TEDH y, en algunos casos no se han cumplido nunca. El incumplimiento se debe en ocasiones a que los procedimientos internos de cambio, revisión o innovación jurídica son más lentos de lo esperado. En este caso, debe ser el Comité de Ministros, en el proceso de supervisión de la ejecución de la sentencia, el que determine como amoldar los mandatos de la sentencia a la realidad interna del Estado ${ }^{80}$.

Sin duda, la aplicación del caso piloto y el compromiso con la mejora del standard ha generado escenarios de éxito. Así, en Kurić y otros contra Eslovenia, de 25 de abril de 2017, en un asunto en el que los demandantes, originarios de la antigua República Federal Socialista de Yugoslavia no habían sido reconocidos como ciudadanos del nuevo Estado, el Comité de Ministros decidió cerrar el expediente de ejecución al comprobar que se habían adoptado las medidas necesarias para dar cumplimiento a la sentencia del Tribunal ${ }^{81}$. En otros asuntos, las soluciones se están demorando más, pero las resoluciones intermedias del Comité de Ministros parecen indicar que se están acercando posiciones y que los Estados están respondiendo, aunque sea lentamente; ejemplos de esta situación sería el cumplimiento de la sentencia Greens y M.T. contra Reino Unido, de 23 de noviembre de 2010, sobre la prohibición general de ejercer el derecho de voto a todos los presos ${ }^{82}$; o, por ejemplo, en el asunto Rutkowski y otros contra Polonia, de 7 de julio de 2015, sobre la excesiva duración de los procedimientos judiciales, el Comité de Ministros también da muestras en sus informes de avances lentos pero en la buena dirección ${ }^{83}$.

contra Hungría, al considerar que el fallo estructural interno había sido remediado con una ley de 2016 dictada en cumplimiento de la STEDH Varga. Así, comunicó al nuevo demandante la necesidad de agotar los instrumentos previstos en la nueva ley antes de acudir al Tribunal.

80 GLAS, L. R. «The Functioning of the Pilot-Judgment Procedure», op.cit., p. 21, considera que sería más adecuado que el TEDH no marcara los plazos, sino que fuera el Comité de Ministros una vez que hubiera establecido contacto con el Estado responsable de la violación. Esto podría favorecer un cumplimiento más realista de las sentencias.

81 Resolución Resolution CM/ResDH(2016)112, de 25 de mayo de 2016.

82 Así se deduce de lo descrito por el Comité de Ministros en un documento adoptado en diciembre de 2017 (http://hudoc.exec.coe.int/eng\#\{\%22EXECIdentifier\%22:[\%22004-2204\%22]\}), consultado el 15 de julio de 2018.

83 Diciembre de 2017, vid en http://hudoc.exec.coe.int/eng?i=004-26436, consultado el 15 de julio de 2018. 
Ahora bien, ¿qué ocurre cuando una sentencia piloto no se cumple adecuadamente?

El caso más claro de esta situación se ha producido respecto de la no ejecución de decisiones judiciales declarada en la sentencia piloto Ivanov contra Ucrania, citada más arriba. Como se explicó, esta sentencia traía causa de la falta de ejecución de sentencias por deudas contraídas por el Estado respecto de los demandantes. La sentencia piloto establecía un periodo de un año desde la firmeza de la decisión para adoptar los remedios internos necesarios para compensar a las víctimas por una ejecución incompleta o inexistente. Pasado el plazo fijado sin que Ucrania adoptara las medidas generales señaladas, el Tribunal reexaminó la situación de los aproximadamente 2500 casos pendientes por las mismas causas. El Tribunal observó que, en algunos de ellos, los demandantes habían llegado a arreglos individualizados con el Estado. Sin embargo, todavía había que dar respuesta a unos 1700 asuntos. Ante esta situación, en febrero de 2012 el Tribunal decidió retomar la tramitación de estos asuntos.

Cinco años más tarde, el 12 de octubre de 2017, la Gran Sala dictó sentencia en el asunto Burmych y otros contra Ucrania, que planteaba cuestiones similares a las estudiadas en la sentencia piloto Yuriy Nikolayevich Ivanov. La demanda Burmych, acompañada de otras 4 similares, formaba parte de un grupo de más de 12.100 demandas repetitivas pendientes ante el Tribunal, todas con origen en el problema sistémico identificado en Ivanov. Así las cosas, la Gran Sala decidió unir las cinco demandas y las 12.000 y picos pendientes y concluyó que todas derivaban de la sentencia Ivanov, concretamente, de la falta de adopción por Ucrania de las medidas generales establecidas. Por ello, decidió archivarlas, en virtud del art. 37.1 c) CEDH, y se las transmitió al Comité de Ministros para que fueran tratadas en el marco de la supervisión de ejecución de las medidas generales establecidas en la sentencia piloto. Hoy en día, el Comité sigue lidiando con la implementación de la sentencia Ivanov y, también, intentando que el Gobierno ucraniano alcance acuerdos individualizados con los más de 12000 demandantes implicados en la sentencia Burmych ${ }^{84}$.

\section{LA TENDENCIA CONSTITUCIONALIZADORA DEL PROCEDIMIENTO PILOTO}

Claramente los casos pilotos, como se ha apuntado, suponen una muestra de la tendencia constitucionalizadora ${ }^{85}$, en el sentido «armonizante» del término, del sistema europeo. Y ello aunque, hasta donde yo se, en sus decisiones sobre casos pilotos el Tribunal haya evitado utilizar el concepto «constitucional», o cualquier de sus variantes ${ }^{86}$. Pero materialmente, el TEDH ha superado, por mandato normativo, los límites declarativos de sus sentencias e incorpora en sus fundamentos jurídicos auténticos mandatos,

84 Parece que el problema de fondo es que Ucrania no cuenta con los fondos necesarios para hacer frente al coste de la implementación de las medidas generales señaladas por el TEDH y el Comité de Ministros que, como se ha dicho, se ha visto obligador a optar en primer término por intentar que el Gobierno ucraniano restablezca los derechos de los demandantes ante Estrasburgo. Cfr. SaAvedra Alessandri, P., Cano Palomares, G. y Hernández Ramos, M. «Repración y Supervisión de Sentencias,», op.cit., p. 226.

85 Claramente, Fyrnys, M. «Expanding Competences by Judicial Lawmaking: The Pilot Judgment Procedure of the European Court of Human Rights,» en German Law Journal, Vol. 12, núm. 05, p. 1233.

86 Cfr. SAdurski, W., «Partnering with Strasbourg...», op. cit., p. 422 
obligaciones positivas, para el Estado parte responsable de la violación del CEDH. El lenguaje utilizado por el Tribunal no sugiere la adopción de medidas, sino que las impone, y así lo traslada, además, a la parte dispositiva de sus sentencias.

El cambio que incorpora la sentencia piloto es que, a diferencia de lo que ocurría con anterioridad, la necesidad de adopción de medidas generales aparece en la parte dispositiva de las sentencias del Tribunal ${ }^{87}$. Así, si antes de Broniowski contra Polonia ${ }^{88}$, el TEDH identificaba que el origen de la violación de un derecho convencional estaba en una disposición general interna, y no en su acto de ejecución, lo refería en los fundamentos jurídicos de la decisión pero no en el fallo, dejando que fuera el Estado o el Comité de Ministros los que tomaran la decisión sobre las medidas. Con la adopción del procedimiento del caso piloto, como señala Garlicki, el TEDH se adentra en la dimensión constitucional de su función, superando los límites de la función de tutela individual ${ }^{89}$, de la tutela subjetiva.

Esta transformación constitucionalizadora no ha gustado a todos, más bien lo contrario. Algunos autores señalan que el procedimiento de caso piloto puede suponer una fuerte injerencia en el principio de subsidiariedad y, sobre todo, en el margen de apreciación de los Estados, principio intrínsecamente vinculado al sistema europeo de tutela. En esta línea, señala Di Marco que las sentencias piloto suponen desbordar la aproximación casuística que caracteriza al $\mathrm{TEDH}^{90}$, ya que este escoge uno o varios casos que analiza y, a partir de las conclusiones adoptadas en él sobre la violación de un derecho convencional generada por una determinada situación fáctica o normativa, extrae conclusiones sobre la compatibilidad con el estándar europeo del resto de supuestos. En este sentido, el TEDH pasa de realizar un control concreto de una actuación individualiza a un control abstracto de lo que califica como un fallo estructural del sistema interno de garantía.

Es cierto que el margen de apreciación es un principio basilar del sistema europeo de garantía que permite hacer efectiva la relación cooperativa ${ }^{91}$ en la tutela de los derechos fundamentales entre TEDH y Estados, y, también, en el cumplimiento de las sentencias. El art. $1 \mathrm{CEDH}$ reconoce una obligación de resultado por la que los Estados parte quedan jurídicamente vinculados a proteger los derechos y libertades recogidos por este instrumento internacional. Ahora bien, el Convenio no prefigura qué herramientas concretas deba adoptar cada Estado para cumplir con dicho resultado (pluralidad del sistema europeo). En este ámbito los Estados cuentan con un más o menos amplio margen de apreciación.

En cambio, cuando decide optar por la aplicación del caso piloto, de acuerdo con las reglas de aplicación de este proceso, el TEDH determina cuáles son las medidas que debe adoptar el Estado para finalizar con la situación lesiva de los derechos convencionales. Visto así, parecería que, en efecto, el TEDH rompe con su principio de actuación de no determinar cómo deben los Estados cumplir con sus obligaciones.

87 Cfr. Garlicki, L. «Broniowski and After: On the Dual Nature of 'Pilot Judgments,'» in Liber Amicorum Luzius Wildhaber, 2007, p. 183.

88 STEDH de Gran Sala de 28 de septiembre de 2005.

89 GARLICKI, L. «Broniowski and After», op.cit. p. 182.

90 Vid. Di Marco, A., «L'État Face Aux Arrêts Pilotes», op.cit., p. 888.

91 Cfr. Fyrnys, M. «Expanding Competences by Judicial Lawmaking», op.cit., p. 259. 
Ahora bien, si se va al examen concreto del procedimiento de los casos piloto, se observa como lo que a priori podría parecer una injerencia excesiva del TEDH en el ámbito propio de actuación del Estado, en realidad, no lo es.

Como se ha visto, en la fórmula estándar del caso piloto, el TEDH estudia el asunto o asuntos que tiene en sus manos y verifica, a través de diferentes evidencias ${ }^{92}$, que se trata de un asunto repetitivo. Ante esta evidencia el TEDH decide que aplicará este particular procedimiento y llevará a cabo el estudio del caso, identificando qué causa «subyacente» o estructural está en el origen de la vulneración, quebrantado el CEDH. A partir de aquí, y al amparo del art. $46 \mathrm{CEDH}$, el TEDH señala cuáles son las medidas qué debe adoptar para poner fin a la violación o violaciones del CEDH, qué debe hacer para restaurar los derechos ya vulnerados y evitar futuras conculcaciones.

Así, a diferencia de lo que ocurría antes de la implementación de este procedimiento, el TEDH en la parte argumentativa (en los fundamentos jurídicos) identifica la causa de la vulneración, como se ha dicho, y también explica cuáles son las medidas que a su parecer debería adoptar el Estado, tal y como establece el art. $61 \mathrm{TEDH}$, cosa que todavía hace de forma cauta, prudente, recordando que sus decisiones son declarativas y que es competencia del Comité de Ministros la función de velar por el correcto cumplimiento de sus sentencias ${ }^{93}$. Ello, no obstante, en la parte dispositiva (en el fallo) el TEDH determina cuales son las medidas que el Estado debe adoptar sin mayores contemplaciones o recatos. El TEDH utiliza un estilo directo, claro e incondicional, precedido de un «el Estado debe». A partir de aquí, la sentencia pasa a manos del Comité de Ministros que es quien tiene reconocida la función de supervisar el correcto cumplimiento de las sentencias ${ }^{94} \mathrm{y}$, en su caso, quien cuenta con herramientas para forzar dicho cumplimiento, tanto jurídicas (art. 46. $3 \mathrm{CEDH}$ ) como políticas.

Este proceder muestra como las sentencias piloto pueden ser vistas como una excepción a la naturaleza propia de las sentencias europeas: carácter declarativo y, por tanto, en principio, su imposibilidad de fijar medidas concretas de reparación. En este sentido, el TEDH da un paso más allá en la determinación del contenido del restitutio in integrum que ya identificó en la sentencia Papamichalopoulos de $1995^{95}$ como la obligación de resultado derivada de una sentencias estimatoria. Si en los últimos años el TEDH había optado, en supuestos excepcionales, por indicar también en la parte dispositiva una obligación concreta al Estado, pero en forma de medida individual ${ }^{96}$, la sentencia piloto es una apuesta clara por dirigir (si no limitar) la respuesta del Estado a la solución adecuada, compatible, con el estándar europeo. Ahora bien, debe señalarse que, aunque el TEDH avanza en la

92 Porque existen demandas previas, porque exista una bolsa ante el TEDH, etc.

93 Muy duro fue el juez ZaGRebelSKi en su voto particular a la segunda sentencia piloto dictada por el TEDH, asunto Hutten-Czapska contra Polonia, de 19 de junio de 2006, quien afirmaba que el hecho de que las medidas a adoptar se incorporaran en el fallo de la sentencia suponía romper con la división de funciones entre el Tribunal y el Comité de Ministros.

94 GARLICKI, L. «Broniowski and After», op.cit., p. 184 señala que durante el proceso de elaboración del Protocolo núm. 14 al CEDH sobrevoló la posibilidad de incorporar explícitamente en el art. $46 \mathrm{CEDH}$ la posibilidad de que el TEDH fuera el que determinara que medidas debía adoptar el Estado para restablecer la violación. Sin embargo, esta opción no fue acogida y solo en el IE (par- 16) se hace un sucinta mención a la posibilidad de crear un procedimiento específico y prioritario para casos que revelaran situaciones estructurales de violación de derechos.

95 STEDH Papamichalopoulos contra Grecia.

96 Vid, por ejemplo, STEDH del Rio Prada contra España, de 10 de julio de 2012 (Sala) y de 21 de octubre de 2013 (Gran Sala). 
determinación del contenido de la obligación de resultado, todavía deja cierto margen de apreciación a los Estados, en el sentido de que indica qué tipo de medidas deberían adoptarse, sin que haya llegado a individualizar totalmente la medida o medidas que deben adoptarse. Podría decirse que el Tribunal señala la tipología, pero no la concreta medida ${ }^{97}$. Pese a esta salvedad, no menor, algunos autores, como por ejemplo, Fyrnys, evidencian que las sentencias del TEDH en los procedimientos piloto suponen extender la parte dispositiva de la sentencia final mucho más allá del caso individual: no solo identifica un problema estructural, sino que además manda (solicita formalmente) al Estado parte demandado que adopte medidas específicas generales y/o individuales, lo que supone, según el citado autor la incorporación en el sistema de «substantively programmed lawmaking obligation»: mandato de actuación normativa (jurídica) al Estado ${ }^{98}$.

Fyrnys considera que las sentencias piloto generan un efecto judicializante sobre la política estatal. Según este autor «by issuing a substantively programmed lawmaking obligation pilot judgments impose the legal arguments on the political process at the supervisory level» ${ }^{99}$. En esta línea, las sentencias piloto suponen que se normativiza la extensión de los efectos vinculantes de las decisiones del TEDH ${ }^{100}$, de hecho, del sistema. En otros términos, cabría entender que el Comité de Ministros, pero previamente el TEDH, cuando establecen las medidas o tipo de medidas que deba adoptar un Estado para poner fin a una falla estructural incompatible con el sistema europeo, están condicionando las opciones políticas de los poderes estatales. De esta forma, una sentencia piloto implicará, normalmente, la adopción de medidas generales por parte del Estado, esto es, la aprobación de leyes o disposiciones generales de rango inferior lo que, en cualquier caso, supone condicionar la agenda política del legislativo y/o del ejecutivo sin que quepa, en estos casos, ni siquiera valorar la oportunidad política (interna) de adoptar determinadas políticas públicas o determinadas medidas normativas. En este caso, una sentencia piloto asume no ya los efectos del legislador negativo propios de los tribunales constitucionales continentales, sino que se convierte en una suerte de legislador positivo. Y lo hace en un proceso de tutela individual de derechos (en una suerte de amparo) que en su transcurso se convierte en un control de convencionalidad de la normativa interna, e incluso a veces indirectamente, de las políticas implementadas por un gobierno. En este sentido, sin duda, el impacto de las sentencias piloto es mucho mayor que las sentencias declarativas al uso del TEDH, superando los efectos inter partes clásicos, y pasando a tener un efecto erga omnes, eso sí, en los confines de un determinado Estado. Tanto es así que Fyrnys afirma que las sentencias piloto son una novedosa estrategia del TEDH para imponer su jurisdicción sobre el proceso legislativo doméstico ${ }^{101}$.

97 STEDH Torregiani contra Italia.

98 Cfr. Fyrnys, M. «Expanding Competences by Judicial Lawmaking», op.cit., p. 1244. Hay que señalar que este autor es especialmente crítico y incluye la duda de si el Tribunal cuenta con la capacidad para saber qué medidas deben adoptarse y cuáles van a ser efectivas en cada caso y respecto de cada Estado (p. 1250).

99 Fyrnys, M. «Expanding Competences by Judicial Lawmaking», op.cit, 1244. Una opinión similar subyace en el trabajo de la profesora Abrisketa Uriarte, J. «Las sentencias piloto: El Tribunal Europeo de Derechos Humanos, de Juez a Legislador,» Revista Española de Derecho Internacional, Vol. 65, no. 1, 2013, p. 73-99.

100 Fyrnys, M. «Expanding Competences by Judicial Lawmaking», op.cit. p. 1233. El TEDH en las sentencias piloto lleva a cabo una función normativa en tanto que le indica a los Estados cuales son las medidas incluso normativas que deben adoptarse, extralimitándose en sus funciones.

101 FYRnYs, M. «Expanding Competences by Judicial Lawmaking», op.cit. p. 1233. 
Y sí, evidentemente, esto lleva a afirmar, como hace Garlicky, que «las sentencias piloto tienen una doble naturaleza ya que son comparables a las sentencias de un Tribunal Constitucional en los llamados «konkrete Normenkontrolle» y el proceso de «constitutional complaint». La combinación de efectos individuales y generales son típicos de este tipo de decisiones y está presente en las sentencias piloto del TEDH ${ }^{102}$. En definitiva, las sentencias piloto han supuesto la entrada del control de convencionalidad abstracto, sin ambages, en el sistema de garantía y enfatizado su función constitucional.

Fyrnys también señala, en la línea de las críticas vertidas por algún juez del TEDH en votos particulares de las primeras sentencias piloto ${ }^{103}$, que, por una parte, se violenta el reparto horizontal de funciones que el Convenio establece entre el tribunal y el Comité de Ministros, en que el primero declara la violación del CEDH y el segundo determina las medidas y vela porque se cumplan. Por otra, rompe con el reparto vertical de competencias entre TEDH y autoridades nacionales, regido, en principio, por una relación de cooperación, en la que debe respetarse el margen de apreciación de los Estados. Ahora bien, y más allá de la aclaración realizada más arriba sobre este principio, el autor acaba aceptando que esta supuesta extralimitación se produce con la cobertura institucional del Comité de Ministros, en referencia a la Res(2004/3), que, recordemos, tiene como objetivo garantizar la efectividad en el medio y largo plazo del sistema europeo.

\section{UN CLARO DESAFÍO A LA FUNCIÓN DE TUTELA INDIVIDUAL}

Como se ha comprobado, según el TEDH la justificación para implementar el procedimiento de casos piloto es que cuando hay una gran cantidad de solicitudes relacionadas con el mismo problema, los demandantes puedan obtener una reparación más rápida a través, sobre todo, del establecimiento de un recurso efectivo en el ámbito doméstico. Esta parece la única solución viable para las demandas repetitivas pendientes, ya que, de lo contrario, quedarían a la espera durante varios años de ser estudiadas.

Pese a las ventajas que presenta el procedimiento piloto, la realidad demuestra que contiene también algunos inconvenientes, especialmente, desde la perspectiva de la función de tutela individual del sistema europeo. Sin pretender hacer ahora un análisis exhaustivo al respecto, sí merece la pena destacar algunos de ellos.

Algunos autores plantean dudas sobre la conveniencia de aplicar los casos piloto a asuntos que deriven de graves violaciones de derechos ya que pueden suponer una denegación de justicia, del derecho a la tutela ${ }^{104}$. Así lo ha puesto de manifiesto, por ejemplo, Dilek Kurban, muy crítica con el hecho de que este tipo de procedimientos se utilicen en asuntos relativos a las violaciones de derechos sistemáticas de los kurdos en Turquía. Negar el acceso a una decisión individualizada de Estrasburgo supone para estas víctimas una verdadera denegación de justicia dado que es evidente que en Turquía no existen

102 Cfr. Garlicki, L. «Broniowski and After», op.cit., p. 186.

103 FYRnYs, M. «Expanding Competences by Judicial Lawmaking», op.cit. p. 1233

104 Parece que de los pocos que han expresado esta crítica ha sido el juez del TEDH Zagrebelski. 
medidas efectivas para la protección de estas personas; de hecho, son las autoridades turcas las que perpetran estas violaciones inmunemente ${ }^{105}$.

Una crítica relevante se refiere a la situación privilegiada en la que se sitúa a la víctima del que es declarado caso piloto respecto de demandantes de otros casos que son suspendidos o inadmitidos. Precisamente una de las «ventajas» destacadas por el TEDH del procedimiento piloto es que puede implicar el aplazamiento o «congelación» de otros asuntos repetitivos, al menos durante el plazo que se conceda al Estado para adoptar las medidas fijadas en la correspondiente sentencia piloto. En principio, como se ha dicho, este aplazamiento aparece como un elemento de persuasión dirigido a las autoridades nacionales para que adopten las medidas oportunas y se eviten nuevas decisiones reprobatorias. Es cierto que durante este periodo se mantiene a los demandantes informados de los progresos en el cumplimiento de las sentencias. Y, en caso de que el TEDH considere que no se está produciendo una evolución acorde con su decisión, puede en cualquier momento reanudar el examen de la causa.

Ahora bien, recuérdese que el caso o casos elegidos para dictar sentencia conllevan, además, medidas individuales para los demandantes, normalmente, aunque no solo, una satisfacción equitativa. Pero ¿qué ocurre con el resto de los demandantes? Es este elemento el que genera problemas desde la perspectiva de la tutela individual, dado que parece que la sentencia piloto hace de más y de menos entre demandantes que reclaman ante la misma situación y por la violación de los mismos derechos. Hay que tener en cuenta, además, que una sentencia piloto puede suponer, al menos durante un tiempo, que nuevos asuntos no sean admitidos por Estrasburgo. Cabe reconocer que se produce una cierta vacatio en la protección de los derechos en el periodo comprendido entre la sentencia y la adopción efectiva de las medidas ordenadas por el TEDH.

En definitiva, por estas razones este sector de la doctrina que critica las sentencias piloto pone el acento en que son un instrumento llamado a incrementar la productividad del $\mathrm{TEDH}^{106}$, y no tanto que sea un mecanismo adecuado de tutela para poner remedio a graves violaciones de derechos fundamentales. Seguramente, esta crítica es cierta, pero no lo es menos que el Tribunal es una instancia subsidiaria de tutela. Y en ello insiste el procedimiento piloto, en intentar que sean los Estados los que tutelen los derechos y libertades de las personas que se encuentran bajo su jurisdicción. Quizá debería darse un trato diferente para aquellos asuntos que, como los planteados por Kurban, son de una gravedad tal que necesitan de un procedimiento específico.

\section{VALORACIONES FINALES}

Sin duda, el procedimiento de caso piloto supone un elemento novedoso y de fuerte impacto en la naturaleza y comprensión del sistema europeo de garantía. Sin embargo, tampoco debe sobredimensionarse su utilización dado que el Tribunal lo ha utilizado en contadas ocasiones, no más de 35, y siempre en supuestos en los que es evidente que el Estado presenta carencias importantes respecto de alguno de los derechos convencionales. En todo

105 Kurban, D., «Forsaking Individual Justice: The Implications of the European Court of Human Rights' Pilot Judgment Procedure for Victims of Gross and Systematic Violations», en Human Rights Law Review, vol. 16, no. 4. 106 Cfr. Kurban, D., «Forsaking Individual Justice», op.cit, p. 759. 
caso, pese a los problemas que pueda tener, y algunos tiene como se ha visto, es un instrumento adecuado a las necesidades del Tribunal y a la situación de algunos sistemas de tutela internos. En favor del Tribunal, y del sistema en general, debe decirse que la adopción del caso piloto forma parte de otra serie de medidas que buscan preservar la existencia del propio sistema europeo. Tanto es así que, si nos basamos en la última declaración política de los Estados, la valoración del resultado de los casos piloto es positiva y están aquí para quedarse. Así ha quedado reflejado en la Declaración de Copenhague aprobada en abril de 2018:

«[The Conference] notes the positive effects of the pilot judgment procedure as a tool for improving national implementation of the Convention by tackling systemic or structural human rights problems».

Esta valoración se debe a que, como se ha visto, la principal consecuencia de la sentencia piloto es la renacionalización de la tutela de los derechos, esto es, hacer que el Estado parte cumpla las obligaciones del art. $1 \mathrm{CEDH}$ y asuma la correcta protección de los derechos vulnerados. Esta dinámica implica, además, que la fase de supervisión del cumplimiento de la sentencia adquiere una relevancia enorme. El Comité de Ministros asume la responsabilidad de lograr que el Estado infractor adopte las medidas necesarias para que pueda producirse la efectiva renacionalización de la tutela de los derechos. Esta tarea no es, ni mucho menos sencilla y requiere no solo de técnica, sino también de altas dosis de diplomacia. Y, claro, exige tiempo, un tiempo que corre en contra de los individuos que siguen viendo vulnerados sus derechos, en una situación en la que el Tribunal, digámoslo así, ya ha declarado todo lo que podía declarar respecto de la compatibilidad del sistema doméstico con el estándar europeo. Por estos motivos la dinámica de devolver al ámbito doméstico la tutela de los derechos debe ser prioritaria e indispensable en un sistema que, si se recuerdan las cifras expuestas al principio de estas páginas, debe hacer frente a un número ingente y creciente de demandas cada año. De ahí la importancia de reforzar y recordar siempre que sea posible que el europeo es un sistema subsidiario que solo debe activarse cuando los remedios internos no funcionen.

El sistema europeo vive en una situación de continua bipolaridad. Por una parte, todo el mundo, incluidos los Estados (al menos, por lo general), se felicitan por que este sea el sistema de tutela internacional, tanto en el ámbito regional como universal, más avanzado desde la perspectiva de la protección individual de los derechos de las personas. Este éxito lleva aparejadas como mínimo tres situaciones concurrentes y que no siempre se favorecen entre ellas: a) una sobrecarga de trabajo sostenida en el tiempo, b) unas expectativas sobre la función del Tribunal en relación con la tutela de derechos, sobre todo en algunas zonas, muy alta; c) pese al reconocimiento de los logros del TEDH en el desarrollo del estándar común europeo de los derechos humanos, a la hora de la verdad, una posición cautelosa, cuando no restrictiva, de los Estados hacia los poderes de actuación del TEDH. Tanto es así que, en las últimas grandes conferencias sobre el futuro del sistema europeo, Interlaken (2010), Izmir (2011), Brighton (2012) y Bruselas (2015), los Estados pusieron especial empeño en reforzar el principio de subsidiariedad en la actuación del TEDH. Y sí, el principio de subsidiariedad debe ser reivindicado porque es consustancial a la naturaleza del sistema de garantía y por ello el Tribunal lo utiliza reiteradamente, especialmente en las sentencias piloto, para recordar a los Estados que la tutela efectiva de los derechos y libertades convencionales esté primero en sus manos. Todo ello, también, en el bien entendido de que el sistema europeo de 
garantías se basa en la responsabilidad compartida del TEDH y los Estados parte del CEDH, como quedó claramente acotado en la Declaración de Bruselas de $2015^{107}$.

Hay que aceptar, sin duda, que el sistema europeo de protección está experimentado un proceso de mutación en detrimento de su naturaleza internacional y en favor de su naturaleza constitucional. Seguramente, esta transformación no se produzca nunca completamente, o no en el corto y medio plazo, pero sí cabe afirmar que la vertiente constitucional irá ganando fuerza, como demuestra la práctica diaria del Tribunal y la descripción de su función que hacen los analistas. El control de convencionalidad sobre los ordenamientos internos tendrá cada vez un impacto mayor, un poder de transformación cada vez más elevado. La autoritas no siempre está acompañada de potestas pero la obligatoriedad de sus sentencias es una realidad a la que el Tribunal ha ido incorporando cada vez más contenidos (recordemos el salto que supone la restitutio in integrum como obligación primera) y que los Estados, aunque a veces con alguna resistencia ${ }^{108}$, acaban asumiendo. Cuanto mayor sea el impacto inicial de una sentencia del Tribunal, menor será su carga de trabajo futuro. Y en esta línea, cuanto más control pueda ejercer en una primera sentencia, esto es, cuanto más integral sea su fiscalización sobre la situación de la tutela de los derechos en un Estado parte, más efectiva será su función de tutela de los derechos convencionales.

TITLE: The pilot judgements as a paradigmatic example of transformation of the European Court of Human Rights.

ABSTRACT: Fifty years after the ECtHR delivered its first judgement, the time has come to rethink the defining function of this jurisdiction. That means recognizing and analyzing in detail the tension between its role as a protector of individual rights and its role as a standard-setting body through which the process of European harmonisation in the field of fundamental rights takes place. This rethinking actually means considering which of the two functions, the protective or the harmonising one, should prevail in determining the position of the Court of Strasbourg in the European judicial area. One of the clearest elements of this transformation of the Court is the pilot judgment procedure, which tests the potential of the European Court as the European Constitutional Court.

RESUMEN: Después de 50 años desde que el TEDH dictara su primera sentencia, ha llegado el momento de replantearse la función definitoria de esta jurisdicción. Esto supone reconocer y analizar con detalle la tensión existente entre su función de tutela y su función como fijadora de estándares a través de los que se produce el proceso de armonización europea en materia de derechos fundamentales. Este replanteamiento supone, en realidad, determinar cual de las dos funciones, la tuitiva o la armonizadora, debe prevalecer en la determinación de la posición del Tribunal de Estrasburgo en el espacio judicial europeo. Uno de los elementos más claros de esta transformación del Tribunal en el espacio europeo de los derechos bumanos es el procedimiento de caso piloto, banco de pruebas de las potencialidades del Tribunal Europeo como Tribunal Constitucional Europeo.

KEY WORDS: European system of protection, European Court of Human Rights, Constitutional Court, pilot judgment, Europe, Human Rights, dialogue among judges, effective remedy, subsidiarity.

PalabRas CLAVE: Sistema europeo de protección, Tribunal Europeo de Derechos Humanos, Tribunal Constitucional, caso piloto, Europa, Derechos Humanos, diálogo judicial, tutela de derechos, subsidiariedad.

FeCHA de ReCEPCión: 16.07.2018 FeCHA DE ACEPTACIÓN: 13.09.2018

107 «High-level Conference on the «Implementation of the European Convention on Human Rights, our shared responsibility», Brussels Declaration, 27 March 2015. https://www.echr.coe.int/Documents/Brussels_Declaration_ENG.pdf

108 Por todos, Popelier, P., Lambrecht, S., y Lemmens, K., Criticism of the European Court of Human Rights : Shifting the Convention System: Counter-Dynamics at the National and EU Level, Antwerp, 2016. 